\title{
Synergetic Modelling of Energy and Resource Efficiency as well as Occupational Safety and Health Risks of Plating Process Chains
}

\author{
Alexander Leiden $^{1}$ (D) $\cdot$ Sebastian Thiede ${ }^{1}$ (D) $\cdot$ Christoph Herrmann $^{1,2}$ (D)
}

Received: 19 March 2021 / Revised: 24 August 2021 / Accepted: 16 October 2021 / Published online: 2 November 2021

(c) The Author(s) 2021

\begin{abstract}
To meet the sustainable development goals of the United Nations, the energy and resource efficiency of industrial processes have to increase, and workplaces have to become decent for the involved workers. Plating process chains are typically associated with high energy and resource demand and the use of hazardous chemicals. For the analysis and improvement of the energy and resource efficiency as well as for modelling the occupational safety and health risks, a variety of separate approaches are available. Combined approaches are not available yet. An agent-based simulation is used as the basis for integrated energy and resource as well as occupational safety and health risk assessment. In particular, an energy and resource flow model provides the life cycle inventory data for an environmental assessment. The integration of a mechanistic inhalation exposure model through a surrogate model approach enables a combined synergetic consideration of environmental and occupational safety and health effects. A simulation case study shows the impact of chrome acid changes in chrome electroplating processes as well as the effect of different rinsing cascade settings and rinsing control strategies.
\end{abstract}

Keywords Energy and resource efficiency $\cdot$ Occupational health and safety $\cdot$ Plating process chain $\cdot$ Simulation

\section{Introduction}

The implementation of the sustainable development goals from the United Nations asks for responsible consumption and production (goal 12), action to combat climate change (goal 13) as well as for decent workplaces (goal 8) [1]. Thus, manufacturing companies have to contribute to these three goals and work on topics to achieve these goals as part of different actions. Plating is a relevant manufacturing process with about 18,000 surface treatment installations in the EU-15 [2]. Each of these installations is embedded in an industrial process chain with pre- and post-treatment processes. However, often interdependencies between different sub-systems of manufacturing systems influence improvement measures' effects on achieving single goals. Therefore,

Alexander Leiden

a.leiden@tu-bs.de

1 Institute of Machine Tools and Production Technology, Chair of Sustainable Manufacturing and Life Cycle Engineering, Technische Universität Braunschweig, Langer Kamp 19b, 38106 Braunschweig, Germany

2 Fraunhofer Institute for Surface Engineering and Thin Films IST, Bienroder Weg 54 E, 38108 Braunschweig, Germany an integrated framework is required to enable synergetic modelling of the energy and resource demand as well as the occupational safety and health risks (OSH). The framework shall reduce the effort for data acquisition, enable the analysis of the current state of a manufacturing system, and identify interdependencies while implementing measures, which might avoid a goal achievement. To ensure a direct applicability of the framework, it is developed in close cooperation with the industrial partner eiffo eG.

Plating processes are energy and resource intensive processes and use chemicals with a potential impact on human and ecotoxicity. The specific energy demand for plating processes is higher than for other common manufacturing processes such as casting or shaping processes $[3,4]$ and hazardous chemicals like hexavalent chromium, cyanides, acids and bases are used [5, 6]. Plating processes can lead to environmental and economic benefits by improving products' performance by reducing friction, wear and corrosion [7]. Thus, future plating process chains have to meet higher safety and occupational standards as well as an energy and resource efficiency targets.

The use of hazardous chemicals in the plating industry raises awareness of labour authorities in most countries. The international labour organisation published international 


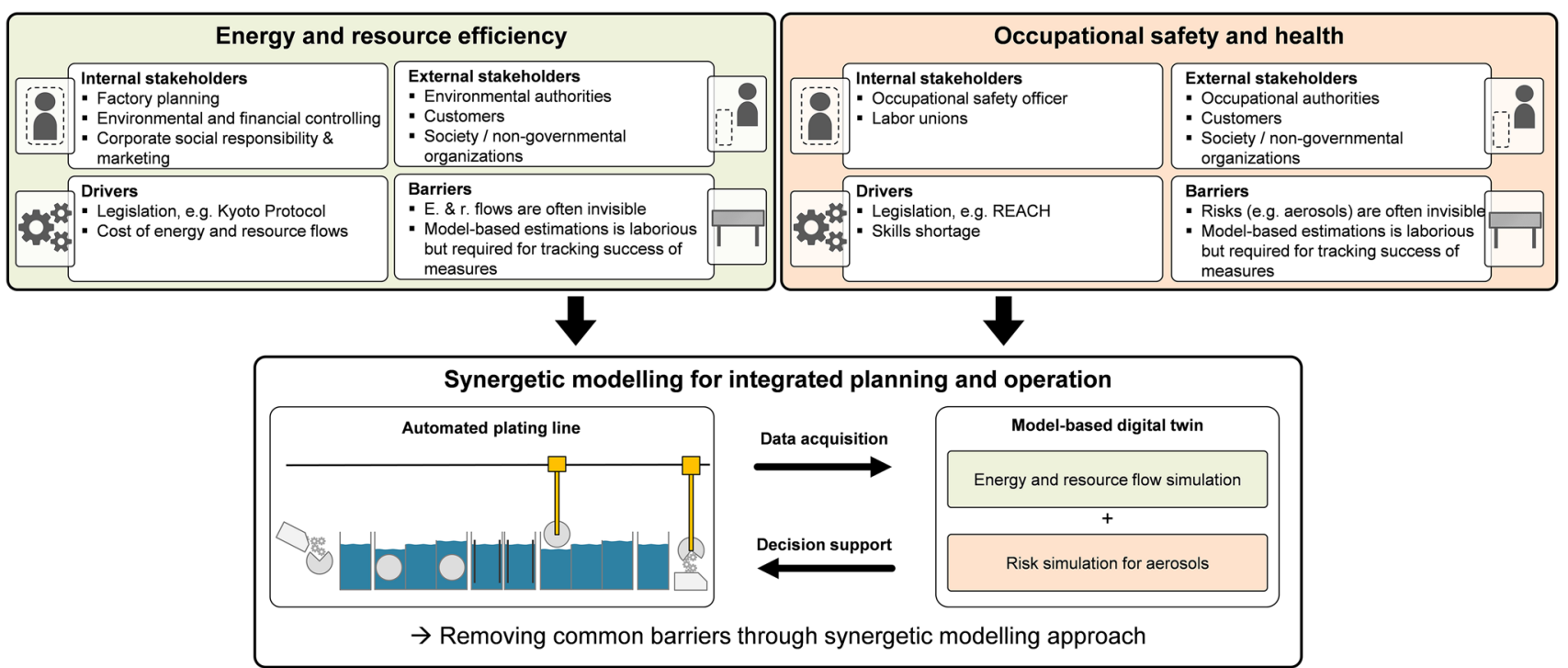

Fig. 1 Motivation and context for synergetic modelling approach (bases on [18])

hazard datasheets for electroplater [8]. In Europe, the European Chemicals Agency (ECHA) restricts the use of hazardous chemicals such as chromium trioxide through an authorisation process [9]. Also in the United States [10] and China [11], the use of such chemicals is restricted through similar mechanisms. For the authorisation process, high process transparency is required, which can be reached through measurements or model-based approaches.

The shift towards industry 4.0, especially towards creating cyber-physical systems and digitals twins, allows decision-makers to test strategies in simulation environments a priori $[12,13]$. Especially model-based digital twins enable predicting the effects of environmental and occupational measures prior implementation [14-16]. The integration of industry 4.0 technologies for occupational health and safety is still at the beginning. Interdisciplinary research is required to develop effective industry 4.0 applications [17].

Figure 1 summarises the internal and external stakeholder as well as the drivers and barriers for energy and resource efficiency as well as of the occupational safety and health. Both topics show similar barriers, especially the lack of transparency. Energy and resource flows as well as risks for workers are often physically invisible and not transparent for decision-makers. For the quantification, models are available for both topics, but their application is often difficult and time-consuming. By combining both models in a digital twin, the efforts can be decreased significantly through synergetic effects. Data has to be acquired only once for both models as well as the models can use the same foundation. This ensures that both models work with the same data and the results are comparable. Specifically, for small and medium-sized enterprises which have limited capacities and often no separate employee for these topics, it eases the implementation of effective measures towards implementing measures to towards implementing the sustainability development goals on a small scale. Therefore, a synergetic simulation approach provides the chance to remove the common barriers by making invisible facts visible and reducing the effort for the application of the model-based approaches in the industry.

\section{Research Background}

The following two subsections provide the research background for models and simulations for the energy and resource efficiency as well as the OSH situation in manufacturing processes. Afterwards, model and simulation coupling approaches are introduced. Finally, the current state of research is summarised, and the research demand is outlined afterwards.

\subsection{Modeling and Simulation of the Energy and Resource Efficiency in Manufacturing}

In the last two decades, many simulation approaches were developed to model the energy and resource efficiency of manufacturing processes [19]. These simulation approaches are used in many industries, but most originally come from discrete manufacturing processes. Table 1 summarises the most relevant research approaches for modelling the energy and resource demand for plating process chains from past research work. In addition, commercially available tools such as Tecnomatix Plant 
Table 1 Models for energy and resource efficiency for manufacturing process chains

\begin{tabular}{lll}
\hline Reference & Scope & Methods \\
\hline $\begin{array}{l}\text { Dong et al.[21] } \\
\text { Heilala et al.[22] }\end{array}$ & $\begin{array}{l}\text { Cleaner production regulations in the electroplating industry } \\
\text { Environmental impact of discrete manufacturing systems }\end{array}$ & $\begin{array}{l}\text { System dynamics } \\
\text { Discrete event model with a life cycle } \\
\text { impact assessment } \\
\text { Kurle [23] }\end{array}$ \\
Leiden [24] & Planning heat flows in production systems & Dynamic heat flow model \\
Thiede [25] & Energy and resource demand of plating process chains & Dynamic energy and resource flow model \\
THERM [26, 27] & Energy flows in manufacturing processes and systems & Dynamic energy flow model \\
Xu [28] & Energy flows in manufacturing systems and building & Dynamic energy flow model \\
\hline
\end{tabular}

Simulation from Siemens also have capabilities to model the energy demand at least by extensions [20].

To assess the impact of cleaner production regulations in the electroplating industry Dong et al. developed a system dynamics approach [21]. Further, Heilala et al. developed a joint discrete event simulation tool for production systems enabling the integration of an environmental impact assessment [22]. Kurle models heat flows in the production system and included electroplating processes into his dynamic simulation approach [23]. In [24], the authors modelled a plating process chain's energy and resource demands part of a cyber-physical production system. The approach from Thiede enables modelling the energy demand in manufacturing systems and the technical building system [25]. Within the THERM project, Wright et al. developed a simulation focusing on the building shell and the technical building system [26]. In the same context, Despeisse et al. were rather focusing on production systems aspects and their interaction with the factory system [27]. Xu et al. model the resource flows in electroplating and rinsing systems for one specific product [28]. However, the approach neglects the energy demand and other systems of the plating line.

\subsection{Modeling and Simulation of Occupational Safety and Health Risks in Manufacturing}

In most countries, labour authorities ask for exposition data before a workplace with hazardous substances is setup. For example the German regulation on hazardous substances requires the execution of a risk assessment. This includes a priori estimation of the exposure and measures in case of exceeded limit values for each workplace [29]. Hence, in the last years, methods and tools were built by researchers and organisations to model the exposition of employees to hazardous substances in an industrial and commercial setting. These models can be used by trained professionals in companies for the risk assessment. A further motivation towards a model-based analysis is that exposure measurements are often considered costly, and the results are only available retrospectively [30].

Table 2 summarises available tools for model-based estimation of the exposure situation in the industry. The tools have different focuses ranging from holistic human health assessments to more specific approaches that consider only one exposure route for specific industry applications.

The United Nations Environment Program and the Society for Environmental Toxicology and Chemistry developed the USEtox model as part of the life cycle initiative [39].

Table 2 Available tools for assessment of occupational safety and health

\begin{tabular}{|c|c|c|c|}
\hline Tool & Scope & Methods & $\begin{array}{l}\text { Refer- } \\
\text { ences }\end{array}$ \\
\hline $\begin{array}{l}\text { ART } \\
\text { Advanced Reach Tool }\end{array}$ & Inhalation exposure & Mechanistic model & {$[31,32]$} \\
\hline $\begin{array}{l}\text { DREAM } \\
\text { DeRmal Exposure Assessment Method }\end{array}$ & Dermal exposure & Structured semi-quantitative assessment & {$[30,33]$} \\
\hline $\begin{array}{l}\text { ECETOC TRA } \\
\text { ECETOC Target Risk Assessment }\end{array}$ & $\begin{array}{l}\text { Inhalation and dermal exposure and } \\
\text { to environment/consumers }\end{array}$ & Source-receptor exposure model & {$[34,35]$} \\
\hline $\begin{array}{l}\text { EUSES } \\
\text { European Union System for the Evaluation } \\
\text { of Substances }\end{array}$ & General exposure to humans & Generic exposure scenarios & [36-38] \\
\hline USEtox & Human health and ecotoxicity & Life cycle impact assessment & [39-41] \\
\hline Stoffenmanager & Inhalation and dermal exposure & Source-receptor exposure model & {$[42,43]$} \\
\hline
\end{tabular}


Fig. 2 Concepts for coupling/ integrating models $[51,52]$
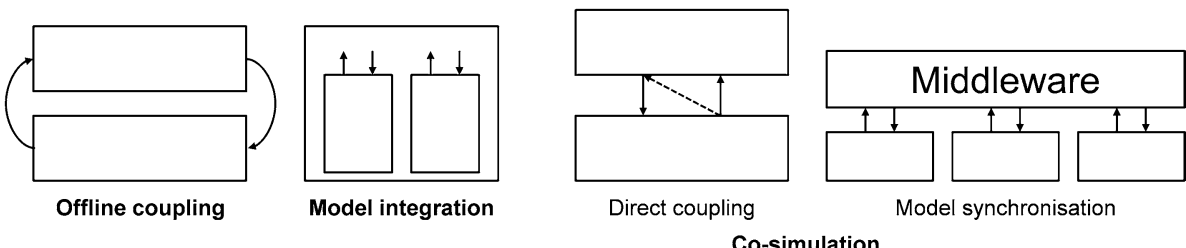

It aims to assess the effects of toxic substances on human health and the ecosystem by providing recommendations for characterisation factors [40]. It can be applied for a wide range of applications with toxic chemicals, such as indoor household use or industrial use in OECD and non-OECD countries [41]. The precision is in the range of a factor between 100 to 1,000 for human health and 10 to 100 for freshwater ecotoxicity [39]. This low precision results from the generic character of this model and prevents a usage for the proposed approach.

The dermal exposure assessment method (DREAM) focuses on dermal exposures to chemical or biological agents in occupational hygiene or epidemiology. Dermal exposure is estimated through a semi-quantitative assessment method [33] for which the users parameterise a set of factors. DREAM has been validated for various chemicals in the manufacturing sector [30].

The Stoffenmanager bases on a source-receptor exposure model [42] that has been introduced by Cherrie et al. [44]. Through a web-based user interface, details of the utilisation of the chemicals are acquired for the calculation of the exposure through inhalation and dermal contact [43]. The ECETOC Target Risk Assessment (ECETOC TRA) bases on similar methodological principles, but also includes exposure to the environment and the consumers [34].

A research group from different European institutions established the Advanced REACH Tool (ART) based on the source-receptor exposure model from the Stoffenmanager and ECETOC TRA. For this, ART combines a mechanistic model with an exposure database to estimate inhalation exposures in an industrial context [31,32]. Currently, it can be considered as the most advanced tool for inhalation exposure estimations. [45]

As the tools ECETOC TRA, Stoffenmanager and ART base on similar principles, various authors compared these tools to measurements in the past. However, no clear statement towards a specific tool is possible, but their simulation results are typically within the same range and close to the measurements $[35,42,45,46]$. More important is their implementation in industrial use than working only with qualitative exposure estimation methods.

The European Union system for evaluating substances (EUSES) holistically assesses the chemicals exposure to human for all relevant exposure routes [36]. Like USEtox, the exposure assessment goes beyond a specific assessment of workers in factories and more focuses on the general risk through the use of hazardous chemicals [37]. Methodologically it bases on generic exposure scenarios [38].

The EMKG Expo tool is not listed in Table 2 as it requires only three input parameters and only estimates if a workplace might is safe or not [47]. The Chesar and the MEASE tool uses ECETROC TRA to quantify the workers' exposure [42] and are not considered separate tools in Table 2. Further, the TREXMO tool only compares the results from different previously presented exposure modelling tools and is no separate tool with own models [48].

Besides the available tools for risk assessment, researchers published approaches for the assessment of the exposure situation. Papadakis and Chalkidou developed a risk assessment approach to estimate the workers individual OSH risk [49]. Their approach focuses on a detailed OSH risks assessment but neglects the dynamics in the productions system as well as environmental aspects. Pilat and Pegnam investigated specifically the hexavalent chromium $(\mathrm{Cr}(\mathrm{VI}))$ emissions of chromium electroplating processes [50]. Based on experiments, they measured $3.81 \mathrm{mg} \mathrm{Cr}(\mathrm{VI})$ emissions per Ampere hour. The details from the models from these two publications are not published nor consider the specific plating sites' boundary conditions. Therefore, they cannot be integrated into another model.

\subsection{Model and Simulation Coupling}

As often different simulation approaches need to be combined, different coupling concepts such as offline coupling, model integration, direct coupling and co-simulation are available to connect different simulation models (Fig. 2) . The selection of a coupling approach depends on the specific models and also their computational efforts.

Surrogate modelling describes the use of a simplified surrogate from a more complex model. This approach's main advantage is that the high computation efforts in complex models can be reduced through data-based methods for the integration as surrogate into other simulation environments. It can be used as basis for a model integration coupling approach. For example, various authors used this approach to build surrogates through machine learning from finite elements models [53-55]. The results are process parameterspecific regression models. 


\subsection{Research Demand for Integrated Modelling}

As shown in the previous chapters, tools for modelling the energy and resource efficiency as well as the OSH situation are available and reached a high degree of maturity. In contrast, combinations of both approaches are rare. An example of a model combination is the approach from Ji et al.. They integrated OSH into a discrete event plant simulation as plant safety simulation and estimated the shopfloor workers' diminished quality of life [56]. For different scenarios, the diminished quality of life is modelled in combination with basic production engineering key performance indicators such as working and waiting time. However, their model does not include environmental aspects.

In summary, no specific modelling framework, which considers energy and resource efficiency as well as OSH aspect, is available for the plating industry. The main three objectives are:

- Development of a framework for synergetic modelling of energy and resource efficiency as well as the OSH situation of the workers in the plating process chain

- Integration of an advanced exposure model into the energy and resource flow model through a matching model coupling approach

- Show the applicability of the developed framework through a case study based on industrial data

\section{Framework for Synergetic Modelling of Energy and Resource Efficiency and Occupational Safety and Health Risks}

For synergetic modelling of energy and resource efficiency and $\mathrm{OSH}$, a framework is required ensuring that the required data are acquired in a structured way and prepared for the use in an integrated simulation environment. As planning experts from different disciplines should use the integrated simulation, the data acquisition and the simulation results visualisation must be as transparent as possible. This fosters the cooperation between the planning experts from the energy and resource efficiency as well as from the $\mathrm{OSH}$ discipline.

The structure of the proposed framework is shown in Fig. 3. The framework and the simulation based on the cyber-physical production systems approach from Leiden et al. [24]. Facility and scenario-specific data are acquired manually with a spreadsheet-based data collection tool from the physical plating process chain. These data are used in the integrated agent-based simulation environment. Also, external data sources can be implemented directly or through a surrogate model approach. The simulation results provide decision support through the integrated environmental, risk and cost analysis capabilities as well as through 2D and 3D visualisations.

\subsection{Physical System: Plating Process Chain}

The plating process chain with all core and peripheral systems forms the framework's basis (Fig. 4). Plating processes with rack carriers are of great concern because the lower automation degree of these plating process chains. Compared to processes with barrels, more workers are involved as the racks need be jigged manually [57]. Further, rack electroplating is commonly used for decorative chromium and hard chromium plating, which are critical from an environmental and $\mathrm{OSH}$ perspective [58]. The cathodic current efficiency is the lowest from all relevant industrial electroplating processes because of the hydrogen formation at the cathode $[59,60]$. Further, chromium electroplating is commonly done with electrolytes containing hexavalent chromium trioxide $\left(\mathrm{CrO}_{3}\right)$, which is highly toxic for humans and the environment $[61,62]$.

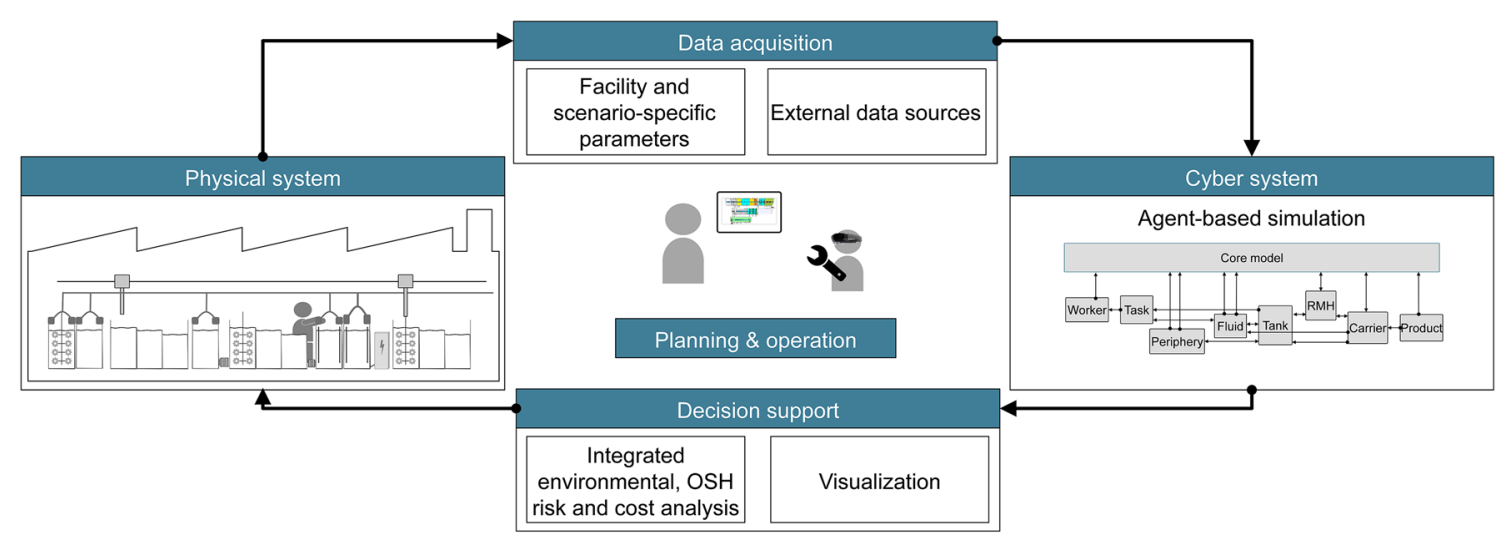

Fig. 3 Framework for integrated modelling of energy and resource efficiency and occupational safety and health risks 


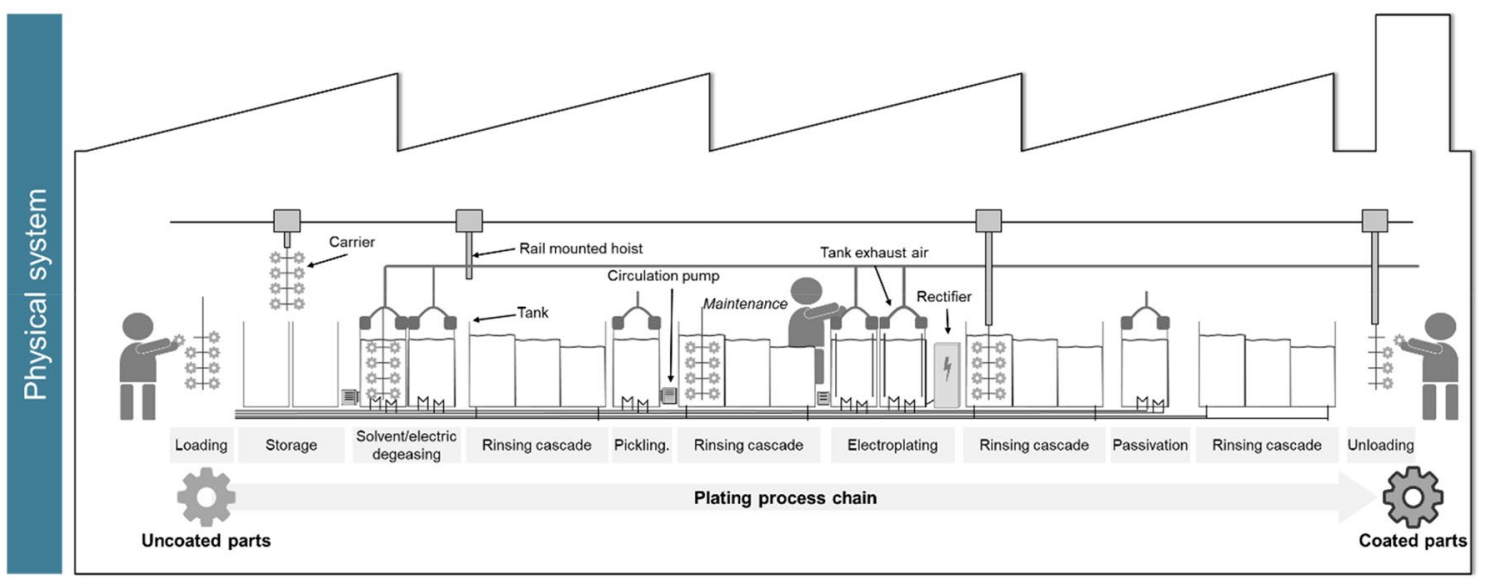

Fig. 4 Details of the physical plating process chain

In the plating process chain the products are cleaned, degreased and pickled before the plating process. For decorative chromium coating first, a nickel layer is applied, followed by a thin chromium layer that does not exceed $1.25 \mu \mathrm{m}$ $[58,63]$. Hard chromium coatings consist of a thicker chromium layer in the range between 2.5 and $500 \mu \mathrm{m}[64,65]$. After the plating process, the parts needs to be rinsed to remove electrolyte residuals.

\subsection{Data Acquisition}

Data are acquired manually through spreadsheets to collect facility and scenario-specific data and automatically implement external data sources (Fig. 5). External data sources can be implemented directly or through a surrogate model approach which is described in Sect 3.2.2.

\subsubsection{Factory and Scenario-Specific Data Acquisition}

For the simulation data from the physical plating process chain are required. A spreadsheet-based input interface has been developed to enable planning experts from different disciplines without an in-depth knowledge of the simulation to parameterise the simulation. The user is guided through six sheets for a full parameterisation:
- Product and production schedule (product's physical properties, carrier properties, time per fluid, etc.)

- Facility and rectifiers (state-based electricity demand, tank properties, rectifier's process parameters, etc.)

- Processing and rinsing media (temperature and volume of fluids, fluid's composition, etc.)

- Workers and jobs (workers daily tasks schedules with time per task)

- Parameter dependent and independent tasks (emission load per task and surrogate models)

- Building and indoor air (temperature, humidity, air changes per hour, etc.)

\subsubsection{Integration of External Data Sources}

External data sources such as impact factors from life cycle inventory databases or cost for energy and resource flows are implemented directly as (impact) factors. As the number of used relevant energy forms and resources in the plating process chain is clear, the effort for the implementation is reasonable.

Beattie et al. showed through biological monitoring that workers are exposed to chromium VI and nickel through inhalation, dermal and ingestion routes [66]. The exposure through the dermal and ingestion route is mainly the result of low hygienic practices. It can be eliminated through simple
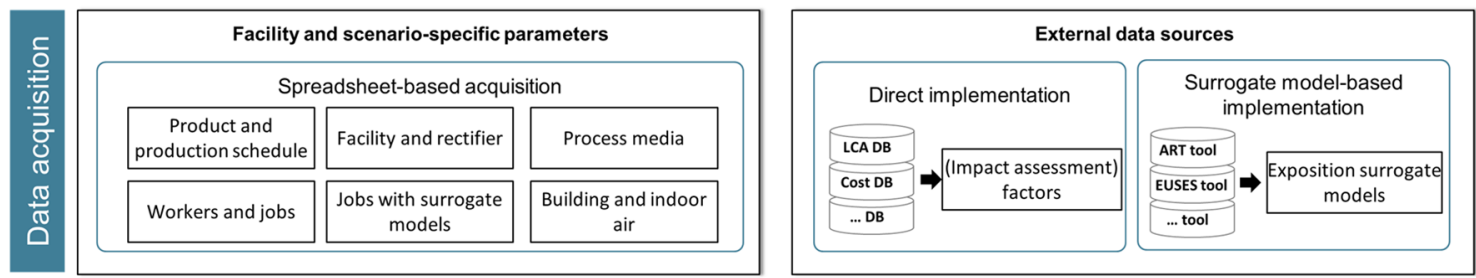

Fig. 5 Data acquisition from the plating process chain and integration of external data sources 
hygienic practices such as wearing gloves while handling contaminated parts and prevent hand to mouth transfers. Eliminating the exposure route through inhalation is more difficult and requires more complex measures. Thus, this exposure route is the focus of the developed framework. As shown in Sect. 2.2, for the inhalation exposure route the ART is currently the most advanced tool. Furthermore, it is freely accessible and approved by European authorities for the authorisation of chemical utilisation. Therefore, it has been selected for the implementation into this new approach.

For the integration of the worker's exposition to hazardous chemicals through aerosols, the ART needs to be coupled with the integrated simulation model. Offline coupling is not applicable as dynamic interdependencies to the process parameters must be considered during the simulation. A direct coupling or through a middleware would require an interface to all involved models. Hence, integrating the ART model into the overall simulation environment is the selected concept for model coupling. However, as no direct access to ART is possible due to the model's different design, it has been decided to integrate the models through a surrogate model approach.

This surrogate model building approach is also used for the integration of the ART. Systematic evaluations of the ART showed that process parameter-specific linear regression models could be built from the ART for specific sets of process parameters. For this, firstly, a case distinction is used, which selects the required regression model depending on the fluid's surface activity and the surface size of the fluid (Fig. 6).

Secondly, a regression model depending on the fluid's $\mathrm{CrO}_{3}$ concentration is applied to calculate the exposition for workers at the plating tanks. Fig. 7 shows the workers' exposition for different sets of process parameters (see Fig. 6). Mainly, large agitated fluid surface areas cause high exposition load significant above the limit value of $5 \mu \mathrm{g} / \mathrm{m}^{3}$.

Process parameters that did not correlate to the exposition modelling results, such as the electrolyte's temperature, were neglected for the surrogate model building approach. So the models could have been kept as simple as possible. In case the simulation is parameterised with untypical process parameters, for instance an electrolyte temperature close to

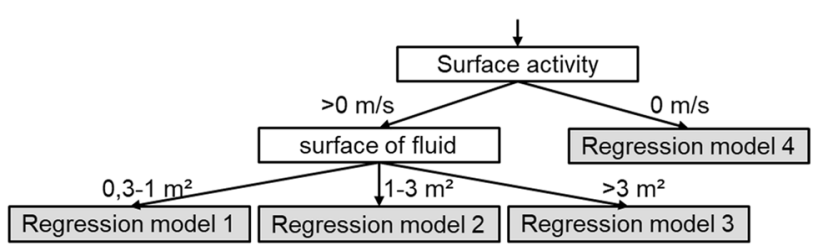

Fig. 6 Process parameter-based case distinction for regression model selection

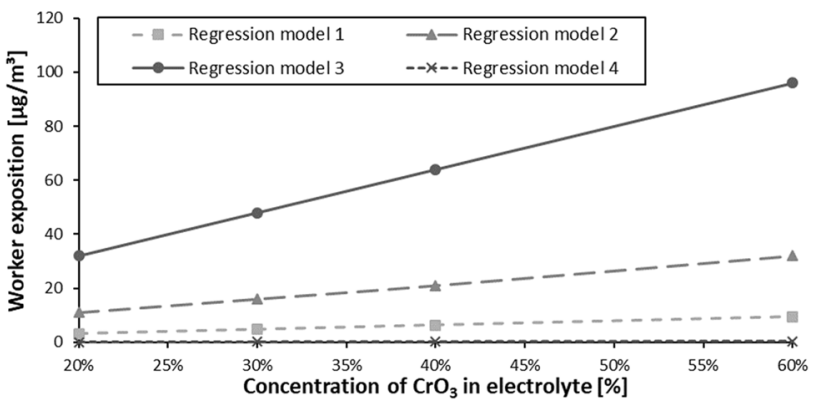

Fig. 7 Regression models for worker expositions and chrome acid concentration

the boiling point, it possibly does not give back realistic values.

\subsection{Integrated Agent-Based Simulation of the Plating Process Chain}

The agent-based multiscale energy and resource flow model combines discrete and continuous simulation paradigms as both can be found in plating process chains. Originally it was built to support the planning and operating a plating process chain. Thus, the model calculates the environmental and economic impact based on the plating process chain's resource flows.

The simulation environment contains eight agent types which are arranged in five layers in Fig. 8. A superior core model controls the overall plating process chain activities. The agent types worker and task from the human resources layer are mainly used to model the OSH aspects. Connections to the agents fluids and tanks in the process chain layer ensure that the OSH situation is modelled depending on the current activities in the process chain. Periphery agents can be connected to the tanks of the process chain. The products are guided with rail mounted hoists (RMH) in carriers through the plating process chain.

The information between single agents and the core model is mainly modelled through messages sent between the agents and public variables that can be accessed from other agents. All required data for an ex-post analysis are stored in an internal database and can be accessed after a simulation run or directly exported for further processing in a spreadsheet file. The data output's temporal resolution can be set before the model run and should be adjusted depending on the modelling time. In case more than two weeks are modelled, the temporal resolution of the data output should be reduced to minutes or hours. Otherwise, the data output becomes too large for spreadsheet files. The computational burden on a standard computer of one simulation run is very low and also remains for simulations of multiple weeks in the range of seconds. Mainly too high temporal resolutions 


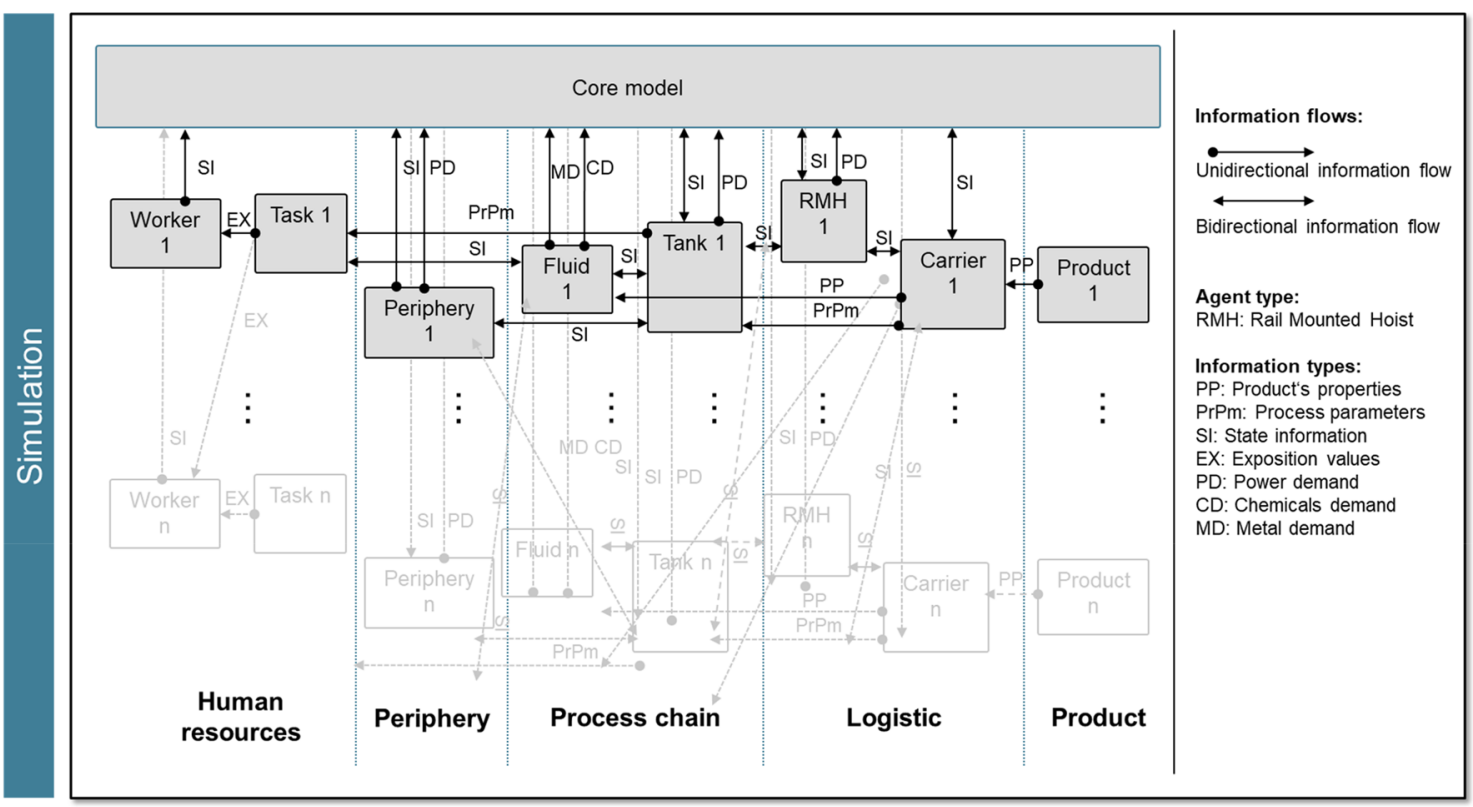

Fig. 8 Multiscale simulation environment including human resources (based on Leiden et al. [24])

can result in delays in writing to the database and exporting to spreadsheets.

The following paragraphs introduce the agent types and explain the used methods to model the energy and resource demand as well as the OSH situation.

\subsubsection{Product}

Products are also modelled as agent. The physical properties of a product, which are required for the simulation, are stored. Examples are the drag-out behaviour, surface, volume, weight and material. These data are mainly required for the energy and resource flow simulation, but indirectly they are used for the exposure estimation (e.g. drag-out influences the concentration of hazardous chemicals in fluids).

\subsubsection{Logistic}

In the logistic layer, the carrier and the rail-mounted hoist (RMH) are responsible to bring the products in carriers to the single process steps/tanks. A defined number of products is filled into the carrier and moved with the RMH through the plating line. The carrier also hands the product's properties and carrier-based process parameters to the tanks.

The RMHs shall manoeuvre the carriers with the products efficiently through the plating line without colliding with other RMHs. To achieve this, the so-called hoist scheduling problem needs to be solved [67]. For this, an algorithm is integrated to ensure that the carriers are handled efficiently and without collisions.

\subsubsection{Process Chain}

The core process chain is built with instances of the agent types tanks and the fluids. As shown in Fig. 4, the plating process chain consists of many different active processes and rinsing processes. The chromium electroplating process and the following rinsing cascade are presented as an example. However, the basic principles remain the same for all active and rinsing processes and can be transferred easily.

In Fig. 9 the general resource flows of the plating process and in the rinsing cascade are shown. Tanks are connected with a fluid which can be classified as active processing fluid and as rinsing fluid. Per processing fluid, up to three additive concentrations are modelled. Rinsing fluids can be parts of a rinsing cascade depending on the plating line layout.

The main driver of the resource flows between the fluids is the carryover which causes a drag-out from a fluid and a drag-in in the following fluid. This mechanism is crucial for the rinsing cascade as the carryover and the revers rinse flow are the only flows which influence the concentrations in the fluids. More details of the model for the fluids and its verification can be found in Leiden et al. [68].

As the rectifiers were identified as the main electricity demand driver, particularly for chromium processes, the electricity demand is calculated with a detailed process model. The basis is the chromium trioxide $\left(\mathrm{CrO}_{3}\right)$ concentration, respectively the chromium acid $\left(\mathrm{H}_{2} \mathrm{CrO}_{4}\right)$ concentration in the electrolyte. The weight ratio between both molecules is 0.85 as the atomic mass of chromium $52 \mathrm{u}$ is much higher than for hydrogen $(1 \mathrm{u})$ and oxygen $(16 \mathrm{u})$ [69]. The plating 


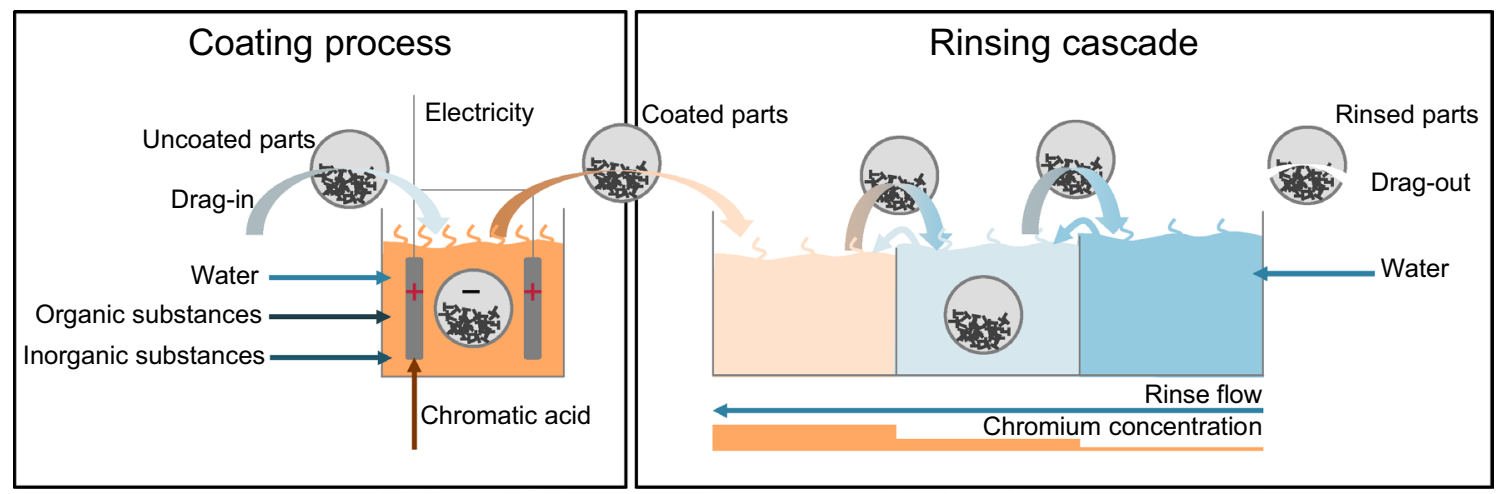

Fig. 9 Resource flow model for coating and rinsing process

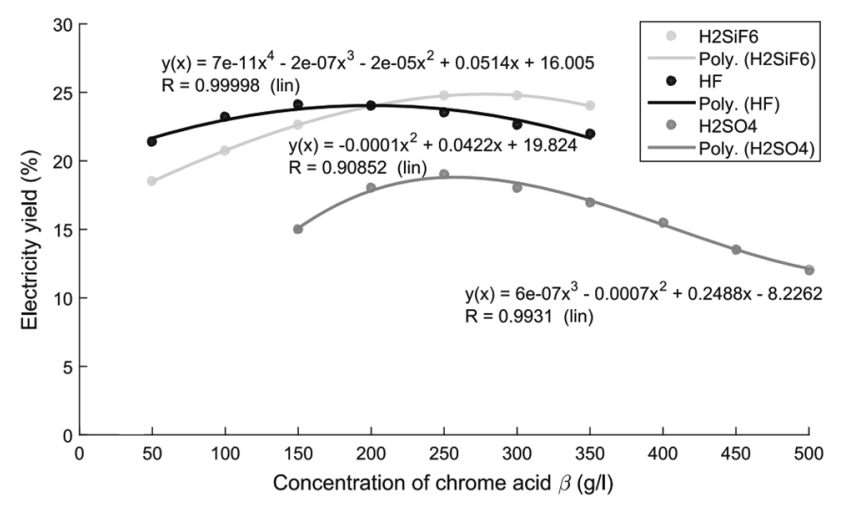

Fig. 10 Energy efficiency and concentration of chrome acid [23, 58, 70]

process's electricity yield depends on the actual chrome acid concentration and the electrolyte type as illustrated in Fig. 10. Based on the electricity yield and the current density, the deposition rate on the products respectively the substrates is estimated [64]. Finally, through this correlations and the rectifier efficiency rating, the energy demand for the rectifiers can be calculated.

With the deposition rate, the processing time for a specific electroplating process can be estimated. Each rectifier also has an energy efficiency ratio. The voltage in the fluid heavily depends on the anode/cathode arrangement in the tank, but typically remains between 8 and $15 \mathrm{~V}$. As a mathematical description would require numerous parameters which are typically not available during the planning phase, the voltage needs to be assumed by experts based on their electroplating experience.

\subsubsection{Periphery}

The agent type periphery is used to model periphery systems such as exhaust air systems, central pumps or plating line-specific water treatment plants. A state-based electricity
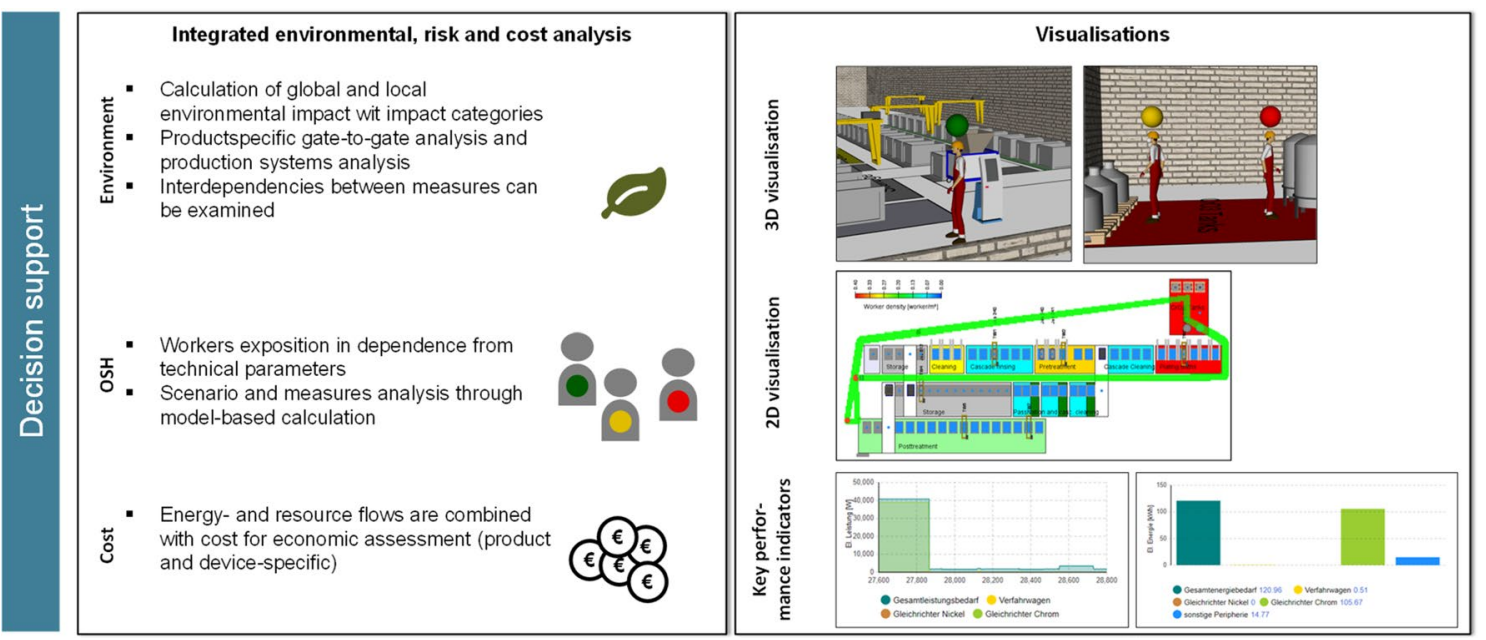

Fig. 11 Decision support through integrated analysis and visualisations 
model is used to model the electricity demand and be operated stand-alone or connected with one or multiple tanks. These tanks can control the periphery systems through state information, e.g. start of exhaust air system due to the start of the plating process.

\subsubsection{Human Resources}

The impact on workers is modelled with the agent type tasks and workers. Workers have a list of tasks to do during a shift and move through the plating line to fulfil these tasks. While working on the task in the plating line, they experience a $\mathrm{Cr}(\mathrm{VI})$ emission load, which depends on the current process parameters and is updated dynamically during the simulation run.

The agent type worker contains a state-chart-based control system which guides the worker through the task list and updates the emission load in case of process parameterdependent tasks. Also, key parameters such as the cumulated or the maximum emission load are stored in this agent type.

Tasks can be associated without an emission load and with an emission load. The emission load can be process parameter-dependent or independent. A specific location in the plating line is selected for each task. The workers move to this location before starting the task.

The tasks which are associated with an exposition to chemicals depend on worker contributing scenarios (WCS). The European Chemicals Agency uses these to authorise processes with substances of very great concern such as hexavalent chromium compounds [71]. The used WCS are summarised in Table 3 . The WCS can be assigned to process categories (PROC), which describe the task from an occupational perspective [72]. As other authors also use the PROC classification (e.g. [73, 74]), a comparison to other modelled approaches becomes possible.

The WCS 4 describes specific tasks in the plating line at the chromium plating fluid for which the worker's exposure highly depends on current process parameters. Consequently, the surrogate model from the ART is used. This task is assigned to a specific tank and so to a specific fluid. By this, the required parameters can be obtained dynamically during a simulation run.

\subsection{Decision Support}

The simulation results are used as the basis for an integrated environmental, occupational risk and cost analysis. Various visualisations support the accessibility of the generated results to the involved internal and external stakeholders (Fig. 11).

\subsubsection{Integrated Environmental, Risk and Cost Analysis}

The simulation model's output data needs to be prepared to support planning decisions in the plating industry. An integrated environmental, occupational risk and cost analysis is conducted after the simulation run. Key performance indicators for an environmental, occupational and economic analysis are calculated and can be used to compare different scenarios.

To estimate the environmental impact, the calculated energy and resource flows from the simulation are used as life cycle inventory data for life cycle assessments from the ISO 14040 [75]. They are multiplied with impact factors for an allocation to the impact category global warming potential. The impact factors can be found in Table 4 and

Table 3 Worker contribution scenarios for chromium plating with $\mathrm{Cr}(\mathrm{VI})$

\begin{tabular}{lll}
\hline Worker contributing scenario & PROC & Scenario description \\
\hline WCS1 Storage raw material & PROC 1 & Delivery and storage of raw material \\
WCS2 Transport & PROC 8b & Transport of chemicals \\
WCS3 Loading of jigs & PROC 4 & Loading and unloading of jigs \\
WCS4 Specific use & PROC 2, PROC 3, PROC 4, & Specific tasks at the plating tank with CrO3 \\
& PROC 13 & \\
WCS5 Sampling & PROC 8b & Control of electrolytes (sample collection) and transport devices \\
WCS 6 Re-filling liquids & PROC 8b & Decanting electrolyte into dosing tanks and re-filling of baths \\
WCS7 Decanting solids & PROC 8b & Decanting of solids \\
WCS 8 Re-filling solids & PROC 8b & Mixing of re-filling electrolyte - solids \\
WCS 9 Regular maintenance & PROC 8b & Regular maintenance and cleaning of equipment \\
WCS 10 Rare maintenance & PROC 8b & Rare maintenance /refurbishment and cleaning of equipment \\
WCS11 Maintenance filter & PROC 8b & maintenances of electrolyte filters \\
WCS12 Quality control & PROC 8b & Quality control by Hull-sheets \\
WCS13 Wastewater management & PROC 8b & Waste and wastewater management \\
\hline
\end{tabular}


Table 4 Impact factors for environmental analysis and cost for financial analysis [61, 76-80]

\begin{tabular}{lll}
\hline & $\begin{array}{l}\text { Global warming poten- } \\
\text { tial } \\
{[\mathrm{kg} \mathrm{CO} 2-\mathrm{eq} .]}\end{array}$ & $\begin{array}{l}\text { Finan- } \\
\text { cial } \\
{[€]}\end{array}$ \\
\hline Electricity $[\mathrm{kWh}]$ & 0.4 & 0.1 \\
Wastewater $[\mathrm{m} 3]$ & 0.26 & 550 \\
CrO3 $[\mathrm{kg}]$ & 5.98 & 3.5 \\
\hline
\end{tabular}

are obtained from the literature and the ecoinvent database $[61,76-78]$.

For the economic analysis, the energy and resource flows are multiplied with prices in the currency Euro. A summary of the cost can be found in Table 4. A price of $550 €$ assumed for the wastewater disposal through a local disposal company. This price is paid by the authors research facility for chromium wastewater and it is in the range of typical wastewater cost for electroplating facilities in Germany (200-800 €/ $\mathrm{m}^{3}$ ) [79]. The price for the freshwater supply of approximately $2 €$ in Germany [80] has been neglected due to the much higher disposal cost. To estimate the price for $\mathrm{CrO}_{3}$ at a purity of $99.8 \%$ market study on business-tobusiness supplier platform was conducted.

Key performance indicators such as the average or the maximum emission load during an 8-h shift are calculated for the assessment of the emission load for each individual worker. The conversion of the emission load into impact factors that describe the effects on the workers' health is difficult due to a lack of available data. It would be critical to accept exposing the workers to a harmful $\mathrm{Cr}(\mathrm{VI})$ emission load to achieve environmentally and financially favourable scenarios from an ethical perspective. Therefore, the limit value of $5 \mu \mathrm{g} / \mathrm{m}^{3}$ has been selected as the value which must not be exceeded. This value is used in most countries as limit value and widely accepted as uncritical for the workers' health. In case a simulation scenario exceeds this value, it cannot be considered for the implementation even it is favourable from an environmental and financial perspective.

\subsubsection{Visualisation}

The high simulation data volume makes it difficult for decision-makers to comprehend the results, especially while the simulation is running. Hence, visualisations are required to make these data accessible to decision-makers [81]. Especially phenomena that are invisible such as electricity flows or aerosols need to be visualised to catch decision-makers' attention.

A 2D map with the plating line layout provides a quick overview of the current situation in the plating process chain. Here, the workers' situation is visualised as a red, orange or green dot, depending on the current emission load. Green dots indicate a non-critical exposure, yellow dots indicate an exposure close to the critical value (4 to $5 \mu \mathrm{g} / \mathrm{m}^{3} \mathrm{Cr}(\mathrm{VI})$ ), and red dots indicate a critical exposure $\left(>5 \mu \mathrm{g} / \mathrm{m}^{3} \mathrm{Cr}(\mathrm{VI})\right)$ that requires immediate measures to reduce the emission load on the workers.

For a better immersion of the decision-makers during the planning and operating of process chains, a 3D visualisation is used. The process chain with all relevant elements such as tanks, fluids, carriers and hoist are modelled as 3D objects and move in a 3D factory environment. Further, the workers' current emission load is indicated by a coloured ball above the workers' head with the same colouring as for the $2 \mathrm{D}$ view.

The visualisation can also be used for workers training and sensitises for the interdependencies of energy and resource efficiency as well as for risks for OSH. Notably, the direct visualisation of the workers' risk situation depending on the process parameters and the current activities enables workers to understand the risk factors for high emission load such as large agitated plating fluids with $\mathrm{Cr}(\mathrm{VI})$.

\section{Case Study: Hard and Decorative Chromium Electroplating}

Researchers, industry and authorities have been searching for alternatives for chromium electroplating with hexavalent chromium over the last decades. However, to date no alternative, which meets the requirements in terms of colour and corrosion resistance, is available [72]. Consequently, it can be assumed that electroplating with hexavalent chromium remains an industrial process and the risks for the workers must be minimised. The introduced framework is applied to a generic combined hard and decorative chromium plating process chain to achieve this. The synergetic modelling benefits are shown in two cases. While case 1 focuses on details from the chrome plating electrolyte model, case 2 focuses on details from the rinsing cascade model. The results of both cases come from the same simulation model and are modelled as part of the whole plating process chain. The application procedure can be transferred to any other active process and rinsing processes in the process chain. In the following subsections first, the case study's general design is presented as the process chain, and the products remain the same for the following detailed cases. Second and third, the detailed cases are shown.

\subsection{Description of Case Study}

A combined electroplating process chain for hard and decorative chromium plating (Fig. 12) is introduced in this case study. The layout bases on electroplating process chains 


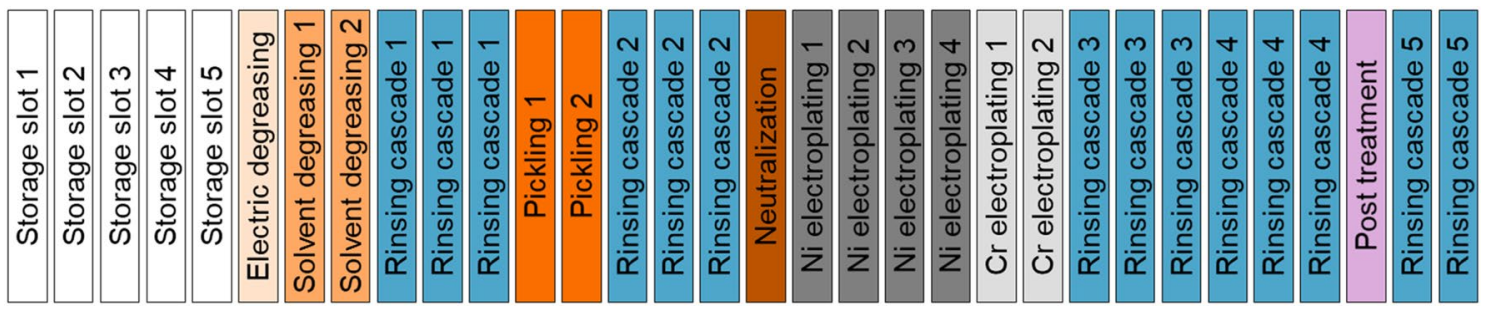

Fig. 12 Plating process chain

from five industrial plating process chains from job platers and industrial platers. Industrial experts confirmed it as a generic representation of this type of electroplating process chains. The advantage of using a generic process chain is the high adaptability to a new electroplating process chain. It can be used for differently scaled plating lines by adjusting the agents' parameters through the spreadsheets in the data acquisition phase. Examples for such parameters are the fluid surface in the tanks or the composition of the electrolyte. Each tank has a capacity of 6001 fluid.

Three different products are used for both cases, as introduced in Table 5. The anonymised car brand logo and generic cube, are coated with a decorative chromium layer which used a nickel coating as base layer. For hard chromium plating, a valve tappet from internal combustion engines is used. Different process parameters are used for different product types. The drag-out volume is calculated with a classification approach [68] and the basis for the resource flow model.

\subsection{Case 1: Risk and Energy Efficiency in Chromium Plating Electrolytes}

In chromium electroplating, the hexavalent chromium compound $\mathrm{CrO}_{3}$ is dissolved in water as chromatic acid and used as metal source [65]. The industrial use of hexavalent chromium compounds is associated with higher lung cancer risk and respiratory diseases [82, 83]. In Europe, the United States and China hexavalent chromium is on priority control/authorisation lists [9-11]. The cathode efficiency of chromium plating only reaches up to $23 \%$ [64] and can be considered as the lowest cathode efficiency for industrial plating processes $[57,60]$. In contrast, nickel electroplating reaches high cathode efficiencies in the range between 95 and $97 \%$ and is less critical from an environmental perspective [58]. Therefore, the focus for this case study is set on chromium plating.

The objective of this case is to calculate the electricity demand and chromium consumption as part of the energy and resource model. For the OSH perspective, the emission load on the workers in the WCS 4 is calculated. In this reference scenario, the influence of different $\mathrm{CrO}_{3}$ concentration on these factors is estimated.

\subsubsection{Reference Scenario}

For the base scenario, an electrolyte with hexafluorosilicic acid $\left(\mathrm{H}_{2} \mathrm{SiF}_{6}\right)$ as catalyst is used. The car brand logo is plated with a thin $1 \mu \mathrm{m}$ decorative chromium layer and the $\mathrm{CrO}_{3}$ concentration is kept steadily and modelled in $50 \mathrm{~g} / \mathrm{l}$ steps between 150 and $300 \mathrm{~g}$ per litre electrolyte. Further process parameters are summarised in Table 6 .

The simulation results are visualised as a diagram with three vertical axes in Fig. 13. $\mathrm{CrO}_{3}$ concentrations higher

Table 5 Products for case study

\begin{tabular}{llll}
\hline & \multicolumn{2}{l}{ Decorative chromium } & Hard chromium \\
\cline { 2 - 3 } & Car brand logo & Cube & Valve tappet \\
\hline Description & Bonnet ornament & $\begin{array}{c}30 \times 30 \times 30 \mathrm{~mm} \\
\text { cube }\end{array}$ & $\begin{array}{c}\text { Part of internal } \\
\text { combustion } \\
\text { engines }\end{array}$ \\
Base Material & & & $42 \mathrm{CrMo} 4$ \\
Ni coating $[\mu \mathrm{m}]$ & ABS & Cf53 & - \\
Cr coating $[\mu \mathrm{m}]$ & 20 & 12 & 10 \\
Surface per product $[\mathrm{mm} 2]$ & 1 & 0.5 & 1.570 \\
Weight $[\mathrm{g}]$ & 25.120 & 5.400 & 31 \\
Products $[1 /$ carrier] & 66 & 208 & 200 \\
Drag-out $[1 /$ carrier] & 40 & 66 & 0.4 \\
\hline
\end{tabular}


Table 6 Process parameters for specific products

\begin{tabular}{|c|c|c|c|}
\hline & \multicolumn{2}{|c|}{ Decorative chromium } & \multirow{2}{*}{$\begin{array}{l}\text { Hard chro- } \\
\text { mium } \\
\text { Valve tappet }\end{array}$} \\
\hline & Car brand logo & Cube & \\
\hline $\mathrm{CrO}_{3}$ concentration $[\mathrm{g} / \mathrm{l}]$ & $150-300$ & & \\
\hline Voltage [V] & 10 & 8 & 15 \\
\hline Plating current [A] & 1,000 & 1,950 & 2,000 \\
\hline Current density [A/dm2] & 10.0 & 56.1 & 62.0 \\
\hline Fluid agitation & On/off & & \\
\hline
\end{tabular}

than $250 \mathrm{~g} / \mathrm{l}$ become unfavourable as the electricity and the $\mathrm{CrO}_{3}$ demand rise while also the workers exposition increases. $\mathrm{A} \mathrm{CrO}_{3}$ concentration of $250 \mathrm{~g} / \mathrm{l}$ would be ideal from an electricity efficiency perspective, while from a $\mathrm{CrO}_{3}$ demand and worker exposition perspective a lower concentration would be favourable. The workers exposition is modelled for steady surface and agitated surfaces as the ART does not allow any further detailing. Chrome plating is associated with heavy hydrogen formulation and exothermic reactions. Thus the fluid's surface will not be fully steady during the plating process. The higher the plating current is in a fluid, the higher are the agitation in the electrolyte and the electrolyte emissions. Especially, the combination of high $\mathrm{CrO}_{3}$ and high plating currents should be avoided.

\subsubsection{Scenario Analysis}

For the scenario analysis first, the product and processing parameters are changed. By this, the difference between decorative and hard chromium process is demonstrated. Second, a different electrolyte type with another catalyst is investigated.

\section{Variation of products}

Different products result in different process parameters and characteristics. In this scenario, the valve tappet is introduced as an example for a hard chromium coating with $10 \mu \mathrm{m}$ and the cube of Cf53 as an example for a generic metal part with a decorative chrome coating. The major different for the hard chrome plating process is the higher plating current as metal is used as substrate instead of ABS. The valve tappet is an example for a typical part from mass production as it is commonly used in internal combustion engines. However, the coating is relatively thin compared to crankshafts or parts from aircraft engines [65].

Figure 14 illustrates the effects of the two alternative products/processes on the electricity and $\mathrm{CrO}_{3}$ demand per product as well as the impact on the workers. The electricity demand per product is approximately ten times higher for the valve tappet, while the $\mathrm{CrO}_{3}$ demand is for the cube approximately three times higher. The curves for the electricity demand and the worker exposition follow the same trend. As the plating current in the tank is higher than in the base scenario, it must be assumed that the electrolyte agitates more, and the expected load is closer to the upper results. A higher $\mathrm{CrO}_{3}$ share is built into the coating during hard chromium process, and relatively less fluid is dragged out.

\section{Change of electrolyte catalyst}

In this scenario, the car brand logo start from the reference scenario is plated, and the same process parameters are used but sulphuric acid $\mathrm{H}_{2} \mathrm{SO}_{4}$ as catalyst for the electrolyte. For this electrolyte, a $\mathrm{CrO}_{3}$ concentration between 250 and $500 \mathrm{~g} / \mathrm{l}$ is required. This has been considered during the simulation and the $\mathrm{CrO}_{3}$ variation is shown in Fig. 15 . The higher $\mathrm{CrO}_{3}$ content leads to a higher drag-out and also to a worker exposition. As this electrolyte type's efficiency is lower and therefore the electricity demand higher, this scenario is unfavourable from all three dimensions.

Figure 16 summarises the results from the reference scenario and the following scenario analysis. The variation due to the variation of the $\mathrm{CrO}_{3}$ concentration are shown as error indicators in the diagram. In all cases the demand for electricity and $\mathrm{CrO}_{3}$ is higher if $\mathrm{H}_{2} \mathrm{SO}_{4}$ is used as catalyst. Although the surface of the valve tappet is significant smaller than of the car brand logo, the electricity demand is in a similar range as this a hard chromium coating is applied. The drag-out of the hard chromium process is low compared

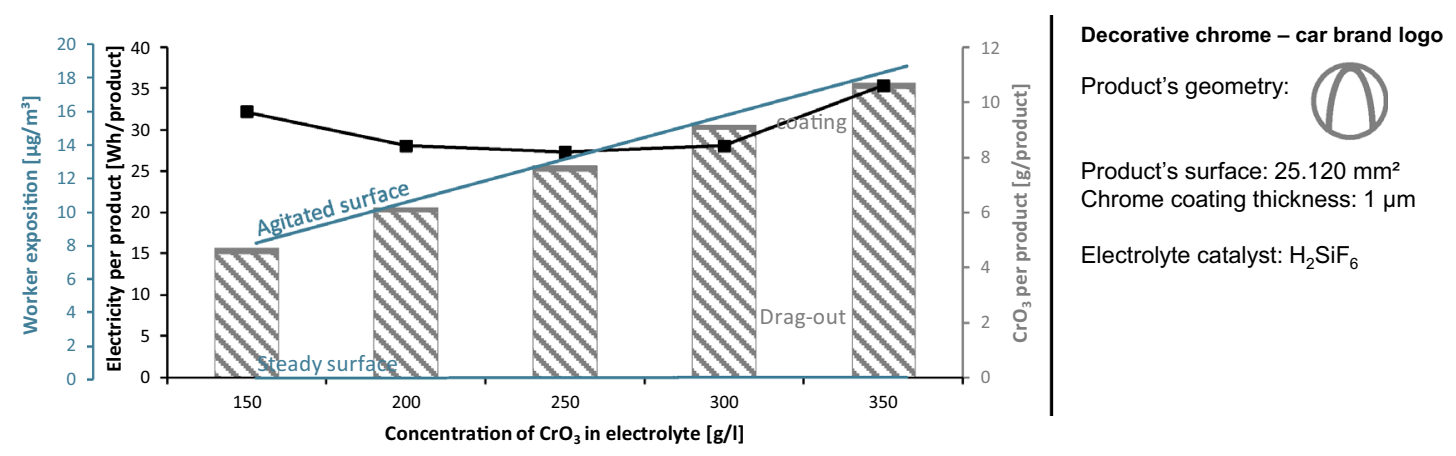

Fig. 13 Influence of different $\mathrm{CrO}$ concentration in the electrolyte on energy and resource efficiency as well as OSH-reference scenario 


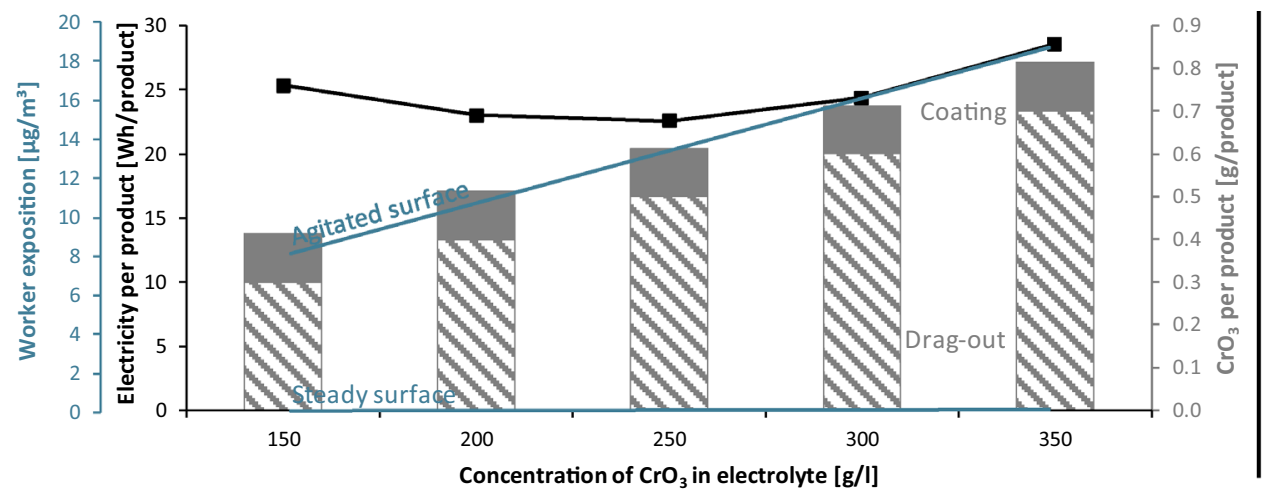

Hard chrome - valve tappet

Product's geometry:

Product's surface: $2,000 \mathrm{~mm}^{2}$

Chrome coating thickness: $10 \mu \mathrm{m}$

Electrolyte catalyst: $\mathrm{H}_{2} \mathrm{SiF}_{6}$
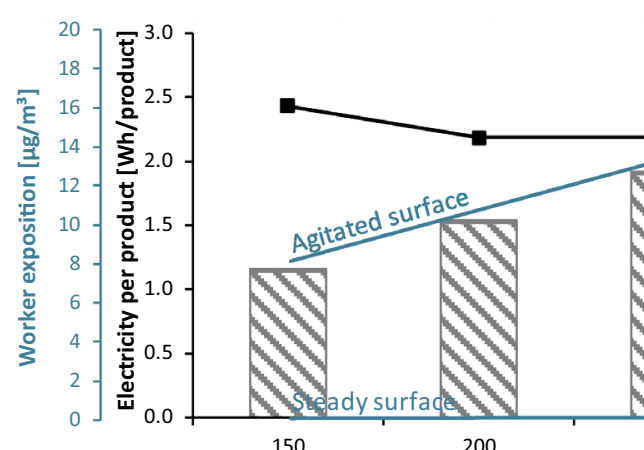

Concentration of $\mathrm{CrO}_{3}$ in electrolyte $[\mathrm{g} / \mathrm{l}]$

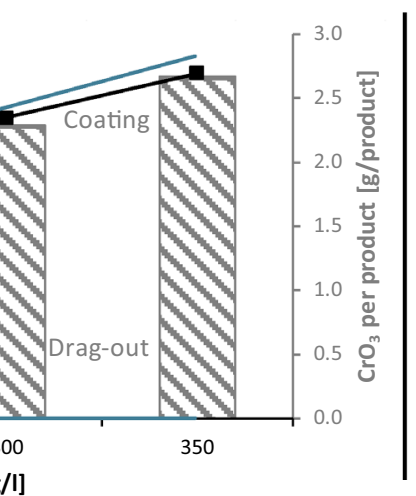

Decorative chrome - cube

Product's geometry:

Product's surface: $5.400 \mathrm{~mm}^{2}$

Chrome coating thickness: $0.5 \mu \mathrm{m}$

Electrolyte catalyst: $\mathrm{H}_{2} \mathrm{SiF}_{6}$

Fig. 14 Influence of different $\mathrm{CrO}_{3}$ concentration in electrolyte on energy and resource efficiency as well as OSH-variation of products

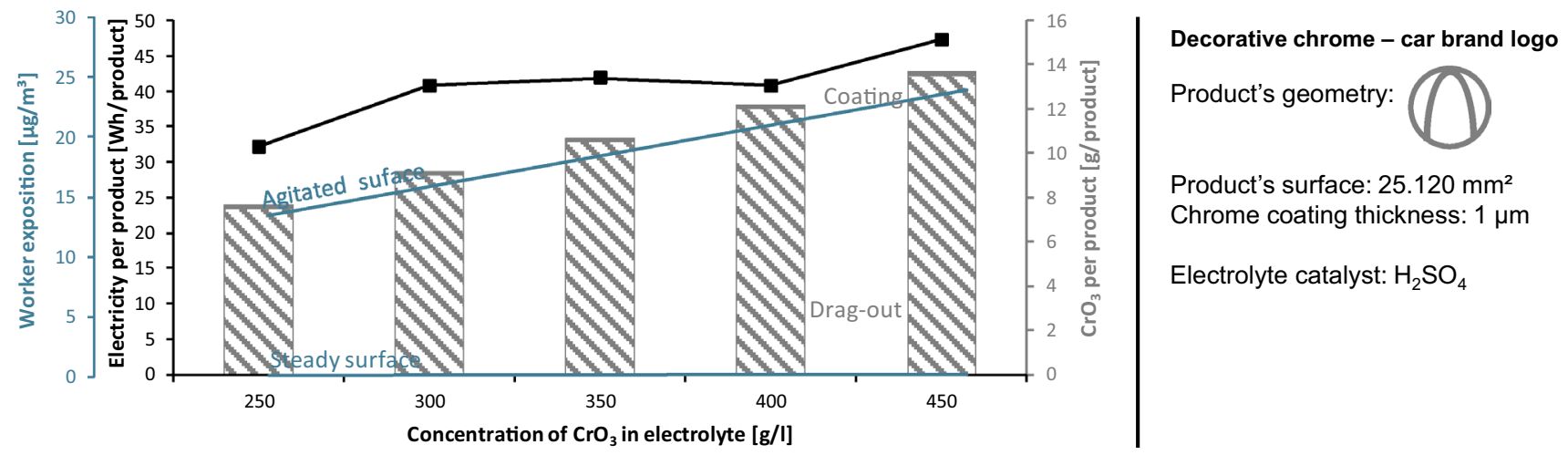

Fig. 15 Influence of different $\mathrm{CrO}_{3}$ concentration in electrolyte on energy and resource efficiency as well as OSH - variation of electrolyte type

to the decorative processes. The workers exposition is independent from the product and mainly depend on the agitation of the surface. Only for an agitated surface, the concentration of the $\mathrm{CrO}_{3}$ becomes relevant.

\subsubsection{Validation}

Validation describes the comparison of the simulation results with the physical system to ensure a sufficient correspondence $[84,85]$. The model for electrolyte and its flows was already validated in a previous study [68]. The obtained results are also in the same range as other publications [86]. Therefore, the validation focuses on the validation of the worker exposition results from the risk analysis which were provided through the surrogate model approach from the ART. For the validation, the hexavalent chromium was measured in airborne particulate matter by ion chromatography and spectrophotometric measurement using diphenyl carbazide according to ISO 16740:2005-02 [87]. The ART allows only steady and agitated surfaces. In chromium 

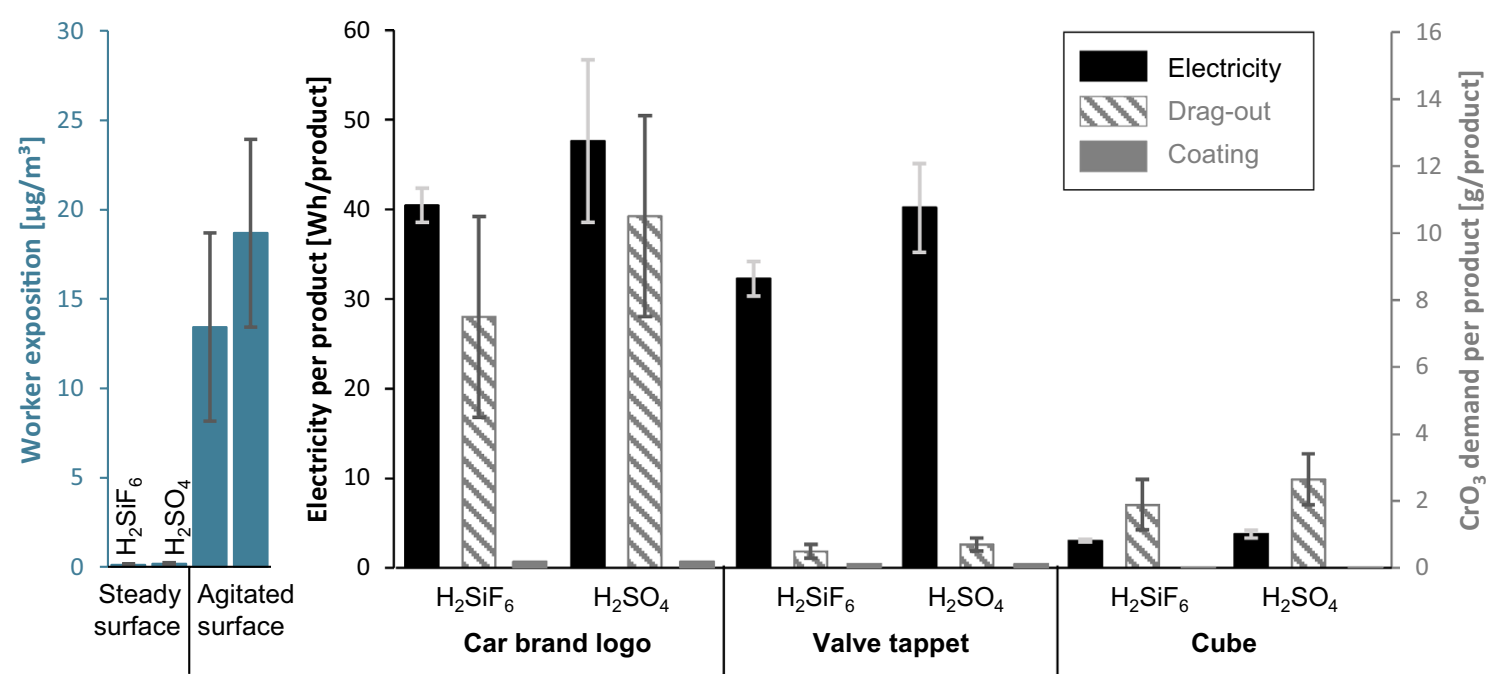

Fig. 16 Summary of the results from reference scenario and the scenario analysis

plating, the surface depends on the activity in the plating fluids, which is a result of the plating current [64]. Hence, measurements were conducted at three different plating currents at two measurement points close to a hexavalent chromium process. Each measurement lasted for one hour and was repeated five times to get significant results.

In Fig. 17, the model results for an agitated and a steady surface are drawn as an upper and lower line of a shaded area. All measurement results at both measurement points are between these two lines, and at both locations the emission load increases with higher plating currents and accordingly an increasing agitation. Similar observations also were made by Pilat and Pegnam [50]. Therefore, the ART's model results can be confirmed as very valid and are in the expected range.

Due to the generic character of the ART a more detailed consideration of the surface movement is not possible but this could be part of further research. It has to be noted that this would also increase the complexity of the models and make it more difficult for interdisciplinary teams to use the simulation model as more details of the process are required. Especially in the planning phase, this data is not available. However, for operation single parts of the simulation could be used to control the local exhaust air.

\subsection{Case 2: Risk and Water Demand in Rinsing Cascades After Chromium Plating Electrolytes}

Products are rinsed to remove the electrolyte and other processing fluids from the surface. By rinsing the risk for the workers who touch the products and finally for customers is reduced, but rinsing is a resource-intensive process. A key parameter for the rinsing process is the rinsing criterion $(\mathrm{R})$. It describes the relationship between the concentration of the relevant substance in the plating bath $\left(\mathrm{c}_{0}\right)$ and the concentration in the rinsing medium $\left(\mathrm{c}_{\mathrm{n}}\right)$ [88]:
Fig. 17 Validation of surrogate model based on ART

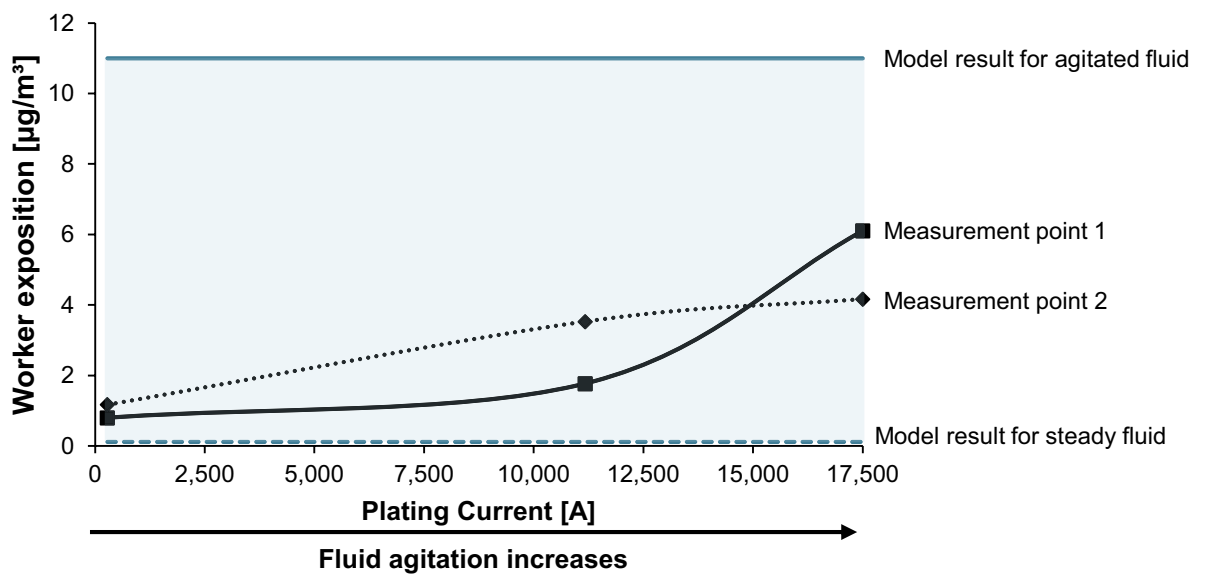

Springer $<$ 与コЕ 
$\mathrm{R}=\frac{c_{0}}{c_{n}}$

The rinsing criterion is set to 10,000 , which is sufficient for the parts from the case study. For critical applications such as medical devices the rinsing criterion can be higher to ensure a maximum of cleanliness.

For this case, the following input parameters are the most important:

- Number of rinsing cascade step: one, two or three steps

- Mode of rinsing cascade control: continuous, time vs. resource flow model controlled

- $\mathrm{CrO}_{3}$ in electrolyte and initial electrolyte concentration in each rinsing step

- Rinsing criterion

The obtained outputs are the required water demand and the risk situation worker at rinsing tanks. This information are the basis for further analysis.

\subsubsection{Reference Scenario}

As industrial lines typically require human interaction mainly for loading and unloading the part, a 3-shift production continuous production has been assumed for the reference scenario. For the reference scenario, it has been assumed that only car brand logo are plated with a cycle time of $1,200 \mathrm{~s}$. The focus of the reference scenario is to investigate the impact of the number of rinsing cascade steps.

It is assumed that $250 \mathrm{~g} \mathrm{CrO}_{3}$ is in the electrolyte per litre electrolyte. To reach the rinsing criterion of 10,000 an electrolyte concentration of $100 \mu \mathrm{l}$ is allowed in the last rinsing cascade step. This results in $\mathrm{CrO}_{3}$ concentration of $2.5 \mathrm{mg}$ in the final cascade and is still above limit values for discharging the rinsing water into public sewage systems [89]. For rinsing cascades with more than one step the rinsing criterion per step can be calculated as n-root. Further, it is assumed that water is added only to the last cascade step and flows through all rinsing steps. If it leaves the first cascade steps, it is disposed through a local disposal company as the concentration is significant too high for disposal through the local public sewage system.

In Table 7, the results from the resource flow model and the environmental and economic assessment are summarised. A single rinsing tank for a rinsing criterion of 10,000 is not possible at an industrial scale considering a tank volume of 6001 . To remove one litre electrolyte, 9,999 1 of water would be necessary. For a two-step cascade system, a rinsing criterion of 100 per cascade step and a three-step cascade system a rinsing criterion of 21.5 per cascade is sufficient. Four-step and even more steps rinsing cascades
Table 7 Environmental impact and cost of rinsing cascade with rinsing criterion of 10,000

\begin{tabular}{lllll}
\hline \multicolumn{4}{c}{ Cascade steps } \\
\cline { 2 - 5 } & 1 & 2 & 3 & 4 \\
\hline Rinsing criterion per cascade & $10,000.0$ & 100.0 & 21.5 & 10.0 \\
Water [1/h] & not possible & 400 & 78 & 36 \\
Water [1/carrier] & & 133 & 26 & 12 \\
Carbon Footprint [€/h] & & 0.094 & 0.020 & 0.009 \\
Carbon Footprint [€/carrier] & & 0.031 & 0.007 & 0.003 \\
Cost [€/h] & & 55.0 & 11.8 & 5.5 \\
Cost [€/carrier] & & 18.3 & 3.9 & 1.8 \\
\hline
\end{tabular}

are rare in the industry due to the high space demand and the low increase of the positive environmental and economic effects.

The carbon footprint and cost are directly correlated to the water demand of the rinsing cascade. In this case, a transparent allocation of the wastewater to the carriers is possible due to the uniform series production. However, it has to be mentioned that the cost only applies in case the rinsing wastewater is handled to a disposal company without further reduction, for example with a vacuum distillation process.

The dynamic approach of the simulation enables to model time-depend concentration progressions in the fluids. Fig. 18 depicts the electrolyte concentration progression for a two and three-step cascade rinsing system. Neglecting the fluctuations the progression in the first rinsing cascade can be described by a logarithmic function and the progression in the further rinsing cascade steps by an S-shaped logistic function. The concentration of less than $100 \mu$ lelectrolyte per 1 rinsing fluid in the final rinsing cascade confirms that the rinsing criterion of 10,000 is secured.

In Fig. 19, the three-step rinsing cascade concentration progression is summarised in one diagram with a logarithmic scale. This diagram shows the delay in the increase in the second and third rinsing cascade step. While the first rinsing cascade step reached a steady-state at 1,200 min, it takes about 2,400 min for the third rinsing cascade step.

As already indicated in Figs. 18, 20 shows the details of the fluctuating concentration. When a carrier is immersed in the rinsing fluid, the electrolyte concentration increases immediately and slowly decreases afterwards during the continuous adding of water to the rinsing fluid. The higher the rinsing criterion per step, the higher the effect and need to be considered while adjusting the amount of rinsing water. For the two-step rinsing cascade, a static calculation of the water throughput results in only $360 \mathrm{l} / \mathrm{h}$ while the dynamic simulation showed that this is not sufficient due to the high fluctuation. However, the average concentration still would 

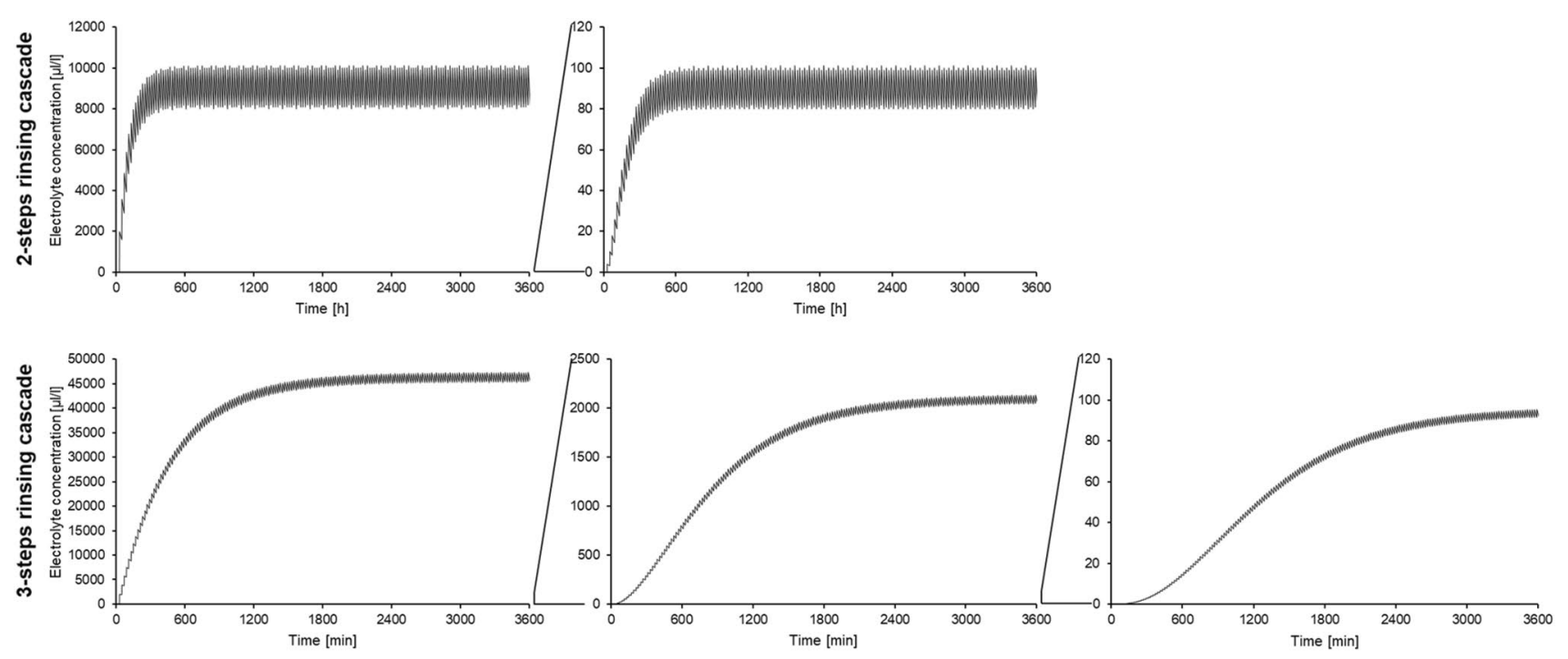

Fig. 18 Electrolyte concentration in two- and three-step rinsing cascade with a continuous flow

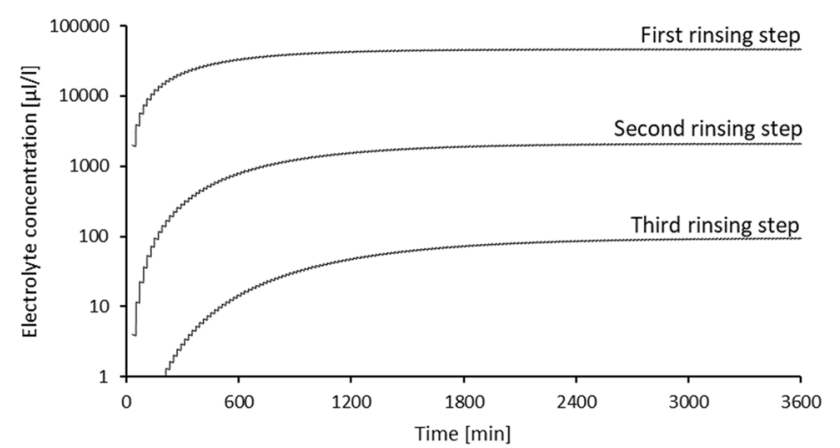

Fig. 19 Electrolyte concentration for three-step rinsing cascade in a logarithmic diagram

fit the rinsing criterion, but the carriers leave the rinsing fluid at the moment with the highest concentration.

Figure 21 shows the logarithmic regression models for the worker exposition at the rinsing tanks dependent on the rinsing criterion. By contrast with the electrolyte models, these models consider that no exhaust hoods are installed at the rinsing tanks. Two regression models are integrated as the surface in rinsing tanks can be steady or agitated. However, the model calculation showed that the emission load on the worker remains significant below critical values. Even for a rinsing criterion of 10 and an agitated surface, the emissions are lower than $0.1 \mu \mathrm{g} / \mathrm{m}^{3}$. For higher and more realistic rinsing criteria and steady surfaces, the worker exposition is out of the range of available analytical measurement devices for detecting airborne hexavalent chromium. Validation of the model results was not carried out as the worker exposition is definitely uncritical and the expected worker exposition through airborne hexavalent chromium is out of the range of the expected results (for the measurement equipment from the previous case the lower measurement limit is $0.02 \mu \mathrm{g} / \mathrm{m}^{3}$ ).

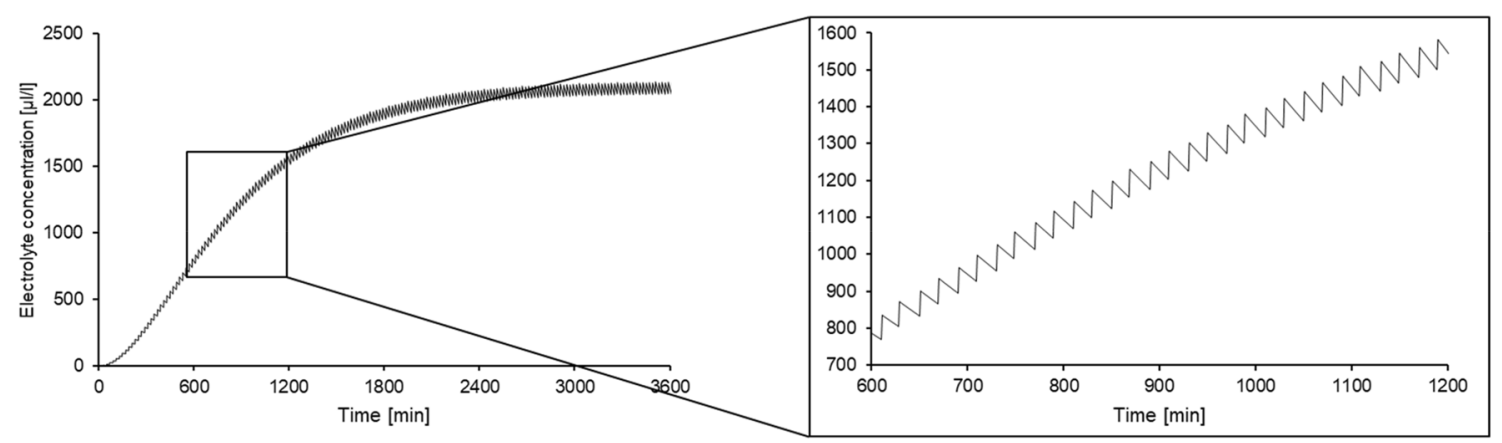

Fig. 20 Zoom into details of electrolyte concentration progression in first rinsing cascade 


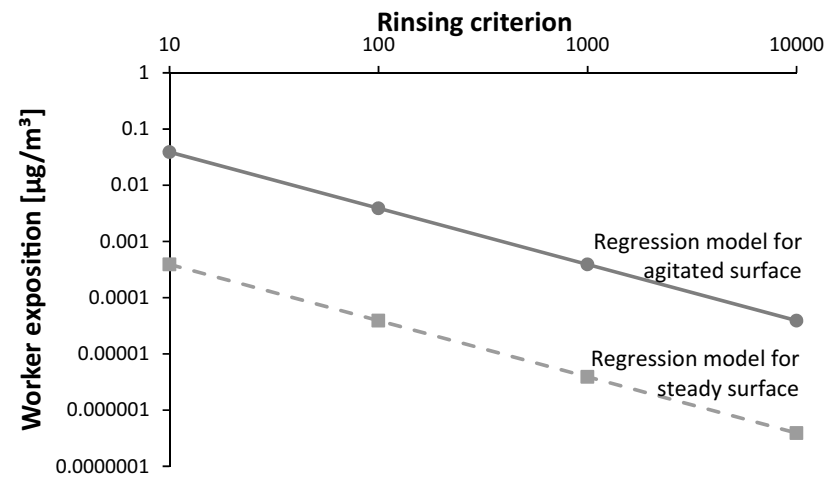

Fig. 21 Exposition at first rinsing cascade tank after Cr VI-based plating

\section{Conclusion and Outlook}

The developed framework for synergetic modelling of energy and resource efficiency and occupational safety and health risks support the implementation of the sustainable development goals with its multi-criteria character. The implementation of the framework is built specifically for decorative and hard chromium process, which are of great concern from an environmental and an OSH perspective. The model for the synergetic modelling bases on an available model for the energy and resource flows and is extended by a surrogate modelling approach with ART to model the OSH situation. The results from the simulation can be used for decision support through an integrated analysis or through different visualisations.

A case study which bases on industrial data showed the benefits of the synergetic modelling approach. The energy and resource efficiency as well as the worker exposition were estimated in a specific case for the chromium plating process and a second case for the following rinsing cascades. Depending on the $\mathrm{CrO}_{3}$ concentration in the electrolyte and the plating current the workers exposition can become critical. Lower $\mathrm{CrO}_{3}$ concentrations also reduce the environmental effects and the cost for the drag-out. At the rinsing cascade no critical worker exposition were estimated, so that the rinsing strategy can be selected without restrictions from the OSH perspective. Using three rinsing cascade steps enables rinsing at a reasonable water demand, and particularly rinsing control mechanisms which work with connected tanks are favourable. The validation of the model results, particularly the worker exposition, secured the simulation results.

A transfer of the simulation to other plating processes such as electroless plating, hot-dip galvanisation or electrophoretic deposition is possible as the implemented model is kept generic for a fast adoption to new processes. The developed 3D visualisation could be integrated into an augmented reality environment to train workers in the plating line. In case a connection to the production IT system is available, live data could be used to warn plating line operators during operation.

Funding Open Access funding enabled and organized by Projekt DEAL. The research results are part of the project "SynARCO Synergetische Analyse und Verbesserung von Ressourceneffizienz und Chemikalienmanagement in der Oberflächentechnik" (Grant ID: 34848/01), sponsored by the Deutsche Bundesstiftung Umwelt. The authors thank Uwe König, Berthold Seßler and Udo Sievers from the cooperation partner eiffo eG.

\section{Declarations}

Conflict of interest On behalf of all authors, the corresponding author states that there is no conflict of interest.

Open Access This article is licensed under a Creative Commons Attribution 4.0 International License, which permits use, sharing, adaptation, distribution and reproduction in any medium or format, as long as you give appropriate credit to the original author(s) and the source, provide a link to the Creative Commons licence, and indicate if changes were made. The images or other third party material in this article are included in the article's Creative Commons licence, unless indicated otherwise in a credit line to the material. If material is not included in the article's Creative Commons licence and your intended use is not permitted by statutory regulation or exceeds the permitted use, you will need to obtain permission directly from the copyright holder. To view a copy of this licence, visit http://creativecommons.org/licenses/by/4.0/.

\section{References}

1. United Nations - Economic and Social Council (2019) Special edition: progress towards the Sustainable Development Goals. https://undocs.org/E/2019/68. Accessed 19 Apr 2020

2. European Comission (2006) Reference document on best available techniques for the surface treatment of metals and plastics. https://eippcb.jrc.ec.europa.eu/reference/BREF/stm_bref_0806. pdf. Accessed 30 Mar 2020

3. Schmid, S. R., \& Jeswiet, J. (2018). Surface treatment and tribological considerations. In J. W. Sutherland, D. A. Dornfeld, \& B. S. Linke (Eds.), Energy efficient manufacturing (pp. 169-195). Wiley.

4. Gutowski, T., Dahmus, J., Thiriez, A. (2006). Electrical energy requirements for manufacturing processes. In 13th CIRP International Conference on Life Cycle Engineering

5. Grace Pavithra, K., Jaikumar, V., Kumar, P. S., et al. (2019). A review on cleaner strategies for chromium industrial wastewater: Present research and future perspective. Journal of Cleaner Production, 228, 580-593. https://doi.org/10.1016/J.JCLEPRO.2019. 04.117

6. Liu, L., \& Ma, X. (2010). Technology-based industrial environmental management: A case study of electroplating in Shenzhen, China. Journal of Cleaner Production, 18, 1731-1739. https://doi. org/10.1016/j.jclepro.2010.06.026

7. Leiden, A., Brand, P.-J., Cerdas, F., et al. (2020). Transferring life cycle engineering to surface engineering. Procedia CIRP, 90, 557-562. https://doi.org/10.1016/j.procir.2020.02.132 
8. International Labour Organisation (2000) International hazard datasheets on occupation: Electroplater. https://www.ilo.org/ wcmsp5/groups/public/---ed_protect/---protrav/---safework/ documents/publication/wcms_193163.pdf. Accessed 24 Jul 2020

9. European Chemicals Agency (2019) Substance Information: Chromium trioxide. Accessed 02 May 2019

10. Baral, A., \& Engelken, R. D. (2002). Chromium-based regulations and greening in metal finishing industries in the USA. Environmental Science \& Policy, 5, 121-133. https://doi.org/10.1016/ S1462-9011(02)00028-X

11. Chemical Inspection and Regulation Service (2018) China MEP Published List of Priority Chemicals. http://www.cirs-reach.com/ news-and-articles/China-MEP-Published-List-of-Priority-Chemi cals.html. Accessed 07 Aug 2020

12. Kang, H. S., Lee, J. Y., Choi, S., et al. (2016). Smart manufacturing: Past research, present findings, and future directions. International Journal of Precision Engineering and Manufacturing-Green Technology, 3, 111-128. https://doi.org/10.1007/ s40684-016-0015-5

13. Acactech National Academy of Science and Engineering (2013) Recommendations for implementing the strategic initiative INDUSTRIE 4.0. https://en.acatech.de/wp-content/uploads/sites/6/ 2018/03/Final_report_Industrie_4.0_accessible.pdf. Accessed 30 Mar 2020

14. Müller, J. M., \& Voigt, K.-I. (2018). Sustainable industrial value creation in SMEs: A comparison between Industry 4.0 and made in China 2025. International Journal of Precision Engineering and Manufacturing-Green Technology, 5, 659-670. https://doi. org/10.1007/s40684-018-0056-Z

15. Herrmann, C., Schmidt, C., Kurle, D., et al. (2014). Sustainability in manufacturing and factories of the future. International Journal of Precision Engineering and Manufacturing-Green Technology, 1, 283-292. https://doi.org/10.1007/s40684-014-0034-Z

16. Park, K. T., Kang, Y. T., Yang, S. G., et al. (2020). Cyber physical energy system for saving energy of the dyeing process with industrial internet of things and manufacturing big data. International Journal of Precision Engineering and Manufacturing-Green Technology, 7, 219-238. https://doi.org/10.1007/s40684-019-00084-7

17. Badri, A., Boudreau-Trudel, B., \& Souissi, A. S. (2018). Occupational health and safety in the industry 4.0 era: A cause for major concern? Safety Science, 109, 403-411. https://doi.org/10.1016/j. ssci.2018.06.012

18. Mittal, V. K., Egede, P., Herrmann, C., et al. (2013). Comparison of Drivers and Barriers to Green Manufacturing: A Case of India and Germany. In A. Y. C. Nee, B. Song, \& S.-K. Ong (Eds.), Proceedings of the 20th CIRP International Conference on Life Cycle Engineering (pp. 723-728). Springer.

19. Duflou, J. R., Sutherland, J. W., Dornfeld, D., et al. (2012). Towards energy and resource efficient manufacturing: A processes and systems approach. CIRP Annals - Manufacturing Technology, 61, 587-609. https://doi.org/10.1016/j.cirp.2012.05.002

20. Prell, B., Stehle, H.-M., Schlegel, A., et al. (2019). Vergleichende Darstellung zweier Werkzeuge zur Simulation energetischer Aspekte in der Produktion. In M. Putz \& A. Schlegel (Eds.), ASIM 2019: Simulation in produktion und logistik (1st ed., pp. 131-142). Auerbach.

21. Dong, X., Li, C., Li, J., et al. (2012). Application of a system dynamics approach for assessment of the impact of regulations on cleaner production in the electroplating industry in China. Journal of Cleaner Production, 20, 72-81. https://doi.org/10.1016/j.jclep ro.2011.08.014

22. Heilala, J., Vatanen, S., Tonteri, H., et al. (2008) Simulation-based sustainable manufacturing system design. In: Mason SJ (ed) Winter Simulation Conference, 2008: WSC 2008; 7 - 10 Dec. 2008, Miami, FL, USA ; incorporate ... the MASM (Modeling and
Analysis for Semiconductor Manufacturing) Conference. IEEE, pp 1922-1930

23. Kurle, D. (2018). Integrated planning of heat flows in production systems. Sustainable production, life cycle engineering and management. Springer.

24. Leiden, A., Herrmann, C., \& Thiede, S. (2020). Cyber-physical production system approach for energy and resource efficient planning and operation of plating process chains. Journal of Cleaner Production. https://doi.org/10.1016/j.jclepro.2020.125160

25. Thiede, S. (2012). Energy efficiency in manufacturing systems. Sustainable production, life cycle engineering and management. Springer.

26. Wright, A. J., Oates, M. R., \& Greenough, R. (2013). Concepts for dynamic modelling of energy-related flows in manufacturing. Applied Energy, 112, 1342-1348. https://doi.org/10.1016/j.apene rgy.2013.01.056

27. Despeisse, M., Oates, M. R., \& Ball, P. D. (2013). Sustainable manufacturing tactics and cross-functional factory modelling. Journal of Cleaner Production, 42, 31-41. https://doi.org/10. 1016/j.jclepro.2012.11.008

28. Xu, Q., Telukdarie, A., Lou, H. H., et al. (2005). Integrated electroplating system modeling and simulation for near zero discharge of chemicals and metals. Industrial and Engineering Chemistry Research, 44, 2156-2164. https://doi.org/10.1021/ ie0495067

29. Bundesanstalt für Arbeitsschutz und Arbeitsmedizin (2017) Gefahrstoffverodnung (GefStoffV). https://www.baua.de/DE/ Themen/Arbeitsgestaltung-im-Betrieb/Gefahrstoffe/Arbeitenmit-Gefahrstoffen/pdf/Gefahrstoffverordnung.pdf?__blob=publi cationFile\&v=5. Accessed 18 Dec 2020

30. de Joode, B. V. W., van Hemmen, J. J., Meijster, T., Major, V., London, L., \& Kromhout, H. (2005). Reliability of a semi-quantitative method for dermal exposure assessment (DREAM). Journal of Exposure Science \& Environmental Epidemiology, 15(1), 111-120. https://doi.org/10.1038/sj.jea.7500369

31. Schinkel, J., Ritchie, P., Goede, H., et al. (2013). The Advanced REACH Tool (ART): Incorporation of an exposure measurement database. Annals of Occupational Hygiene, 57, 717-727. https:// doi.org/10.1093/annhyg/mes103

32. Schinkel, J., Fransman, W., McDonnell, P. E., et al. (2014). Reliability of the advanced REACH tool (ART). Annals of Occupational Hygiene, 58, 450-468. https://doi.org/10.1093/annhyg/ met081

33. Van-Wendel-de-Joode, B., Brouwer, D. H., Vermeulen, R., et al. (2003). DREAM: A method for semi-quantitative dermal exposure assessment. Annals of Occupational Hygiene, 47, 71-87. https://doi.org/10.1093/annhyg/meg012

34. Urbanus, J., Henschel, O., Li, Q., et al. (2020). The ECETOCtargeted risk assessment tool for worker exposure estimation in REACH registration dossiers of chemical substances-current developments. International Journal of Environmental Research and Public Health. https://doi.org/10.3390/ijerph17228443

35. Landberg, H. E., Hedmer, M., Westberg, H., et al. (2019). Evaluating the risk assessment approach of the REACH legislation: a case study. Ann Work Expo Health, 63, 68-76. https://doi.org/10. 1093/annweh/wxy090

36. Lijzen, J., Rikken, M. (2004). European Union System for the Evaluation of Substances 2.0 (EUSES 2.0)

37. Attias, L., Boccardi, P., Boeije, G., et al. (2005). European union system for the evaluation of substances: The second version. Chemosphere, 59, 473-485. https://doi.org/10.1016/j.chemosphere. 2005.01.062

38. Vermeire, T. G., Jager, D. T., Bussian, B., et al. (1997). European union system for the evaluation of substances (EUSES). Principles and structure. Chemosphere, 34, 1823-1836. https://doi.org/10. 1016/S0045-6535(97)00017-9 
39. Rosenbaum, R. K., Bachmann, T. M., Gold, L. S., et al. (2008). USEtox-the UNEP-SETAC toxicity model: Recommended characterisation factors for human toxicity and freshwater ecotoxicity in life cycle impact assessment. International Journal of Life Cycle Assessment, 13, 532-546. https://doi.org/10.1007/ s11367-008-0038-4

40. Rosenbaum, R. K., Huijbregts, M. A. J., Henderson, A. D., et al. (2011). USEtox human exposure and toxicity factors for comparative assessment of toxic emissions in life cycle analysis: Sensitivity to key chemical properties. International Journal of Life Cycle Assessment, 16, 710-727. https://doi.org/10.1007/ s11367-011-0316-4

41. Fantke, P., Bijster, M., Hauschild, M.Z., et al. (2017) USEtox® 2.0 Documentation (Version 1.00). USEtox ${ }^{\circledR}$ Team

42. Cherrie, J. W., Fransman, W., Heussen, G. A. H., et al. (2020). Exposure models for REACH and occupational safety and health regulations. International Journal of Environmental Research and Public Health. https://doi.org/10.3390/ijerph17020383

43. Marquart, H., Heussen, H., Le Feber, M., et al. (2008). "Stoffenmanager", a web-based control banding tool using an exposure process model. Annals of Occupational Hygiene, 52, 429-441. https://doi.org/10.1093/annhyg/men032

44. Cherrie, J. W., \& Schneider, T. (1999). Validation of a new method for structured subjective assessment of past concentrations. Annals of Occupational Hygiene. https://doi.org/10.1093/ annhyg/43.4.235

45. Riedmann, R. A., Gasic, B., \& Vernez, D. (2015). Sensitivity analysis, dominant factors, and robustness of the ECETOC TRA v3, Stoffenmanager 4.5, and ART 1.5 occupational exposure models. Risk Analysis, 35, 211-225. https://doi.org/10.1111/risa.12286

46. Landberg, H. E., Westberg, H., \& Tinnerberg, H. (2018). Evaluation of risk assessment approaches of occupational chemical exposures based on models in comparison with measurements. Safety Science, 109, 412-420. https://doi.org/10.1016/j.ssci.2018. 06.006

47. Bundesanstalt für Arbeitsschutz und Arbeitsmedizin (2017) EMKG-Expo-Tool 2.0. Bundesanstalt für Arbeitsschutz und Arbeitsmedizin (BAuA)

48. Savic, N., Racordon, D., Buchs, D., et al. (2016). TREXMO: a translation tool to support the use of regulatory occupational exposure models. Annals of Occupational Hygiene, 60, 991-1008. https://doi.org/10.1093/annhyg/mew042

49. Papadakis, G. A., \& Chalkidou, A. A. (2008). The exposuredamage approach in the quantification of occupational risk in workplaces involving dangerous substances. Safety Science, 46, 972-991. https://doi.org/10.1016/j.ssci.2007.11.009

50. Pilat, M. J., \& Pegnam, R. C. (2006). Particle emissions from chrome plating. Aerosol Science and Technology, 40, 639-648. https://doi.org/10.1080/02786820600763020

51. Thiede, S., Schönemann, M., Kurle, D., et al. (2016). Multi-level simulation in manufacturing companies: The water-energy nexus case. Journal of Cleaner Production, 139, 1118-1127. https://doi. org/10.1016/j.jclepro.2016.08.144

52. Schönemann, M. (2017). Multiscale simulation approach for battery production systems. Sustainable production, life cycle engineering and management. Springer.

53. Yan, W., Lin, S., Kafka, O. L., et al. (2018). Data-driven multiscale multi-physics models to derive process-structure-property relationships for additive manufacturing. Computational Mechanics, 61, 521-541. https://doi.org/10.1007/s00466-018-1539-z

54. Hürkamp, A., Dér, A., Gellrich, S., et al. (2020). Integrated computational product and production engineering for multi-material lightweight structures. International Journal of Advanced Manufacturing Technology, 110, 2551-2571. https://doi.org/10.1007/ s00170-020-05895-6
55. Hürkamp, A., Gellrich, S., Ossowski, T., et al. (2020). Combining simulation and machine learning as digital twin for the manufacturing of overmolded thermoplastic composites. JMMP, 4, 92. https://doi.org/10.3390/jmmp4030092

56. Ji, Z., Pons, D. J., \& Pearse, J. (2020). Integrating occupational health and safety into plant simulation. Safety Science, 130, 104898. https://doi.org/10.1016/j.ssci.2020.104898

57. Kanani, N. (2004). Electroplating: Basic principles, processes and practice. Elsevier.

58. Dennis, J. K., \& Such, T. E. (1986). Nickel and chromium plating (2nd ed.). Butterworths.

59. Jelinek TW (2013) Practical electroplating [Praktische Galvanotechnik], 7th edn. Lehrbuchreihe Galvanotechnik. Leuze, Bad Saulgau

60. Pletcher, D., \& Walsh, F. C. (1993). Industrial electrochemistry (2nd ed.). Blackie Academic \& Professional.

61. Anger, G., Halstenberg, J., Hochgeschwender, K., et al. (2000) Chromium Compounds. In: Ullmann's Encyclopedia of Industrial Chemistry. Wiley-VCH Verlag GmbH \& Co. KGaA

62. Kim, H., Lee, S., \& Jang, B. (2004). Subchronic inhalation toxicity of soluble hexavalent chromium trioxide in rats. Archives of Toxicology, 78, 363-368. https://doi.org/10.1007/ s00204-004-0553-4

63. Gianelos L (1990) Decorative Chromium Plating. In: Wood WG (ed) Surface cleaning, finishing and coating, 9. ed., 4. print. American Society for Metals, Metals Park, Ohio, pp 188-198

64. Lausmann GA, Horsthemke H (2007) Chromium plating, 1st edition. Schriftenreihe Galvanotechnik und Oberflächenbehandlung, vol 36. Leuze, Bad Saulgau

65. Chessin H, Fernald EH (1990) Hard Chromium Plating. In: Wood WG (ed) Surface cleaning, finishing and coating, 9. ed., 4. print. American Society for Metals, Metals Park, Ohio, pp 170-187

66. Beattie, H., Keen, C., Coldwell, M., et al. (2017). The use of bio-monitoring to assess exposure in the electroplating industry. Journal of Exposure Science \& Environmental Epidemiology, 27, 47-55. https://doi.org/10.1038/jes.2015.67

67. Bloch, C., Bachelu, A., Varnier, C., et al. (1997). Hoist scheduling problem: state-of-the-Art. IFAC Proceedings Volumes, 30, 127-133. https://doi.org/10.1016/S1474-6670(17)42709-1

68. Leiden, A., Kölle, S., Thiede, S., et al. (2020). Model-based analysis, control and dosing of electroplating electrolytes. International Journal of Advanced Manufacturing Technology. https://doi.org/ 10.1007/s00170-020-06190-0

69. Haynes WM, Lide DR (eds) (2015) CRC handbook of chemistry and physics: A ready-reference book of chemical and physical data, 96. ed., 2015-2016. CRC Press

70. Lausmann GA, Unruh JNM (2006) Die galvanische Verchromung: Mit 66 Tabellen, 2., komplett überarb. Aufl. Schriftenreihe Galvanotechnik und Oberflächenbehandlung, vol 35. Leuze, Bad Saulgau

71. European Chemicals Agency (2017) How to apply for authorisation. https://echa.europa.eu/documents/10162/13637/apply_for authorisation_en.pdf. Accessed 03 Dec 2020

72. European Chemicals Agency (2015) Guidance on Information Requirements and Chemical Safety Assessment Chapter R.12: Use description. https://echa.europa.eu/documents/10162/13632/infor mation_requirements_r12_en.pdf. Accessed 03 Dec 2020

73. Kupczewska-Dobecka, M., Czerczak, S., \& Jakubowski, M. (2011). Evaluation of the TRA ECETOC model for inhalation workplace exposure to different organic solvents for selected process categories. International Journal of Occupational Medicine and Environmental Health, 24, 208-217. https://doi.org/10.2478/ s13382-011-0021-3

74. Roth, G. A., Geraci, C. L., Stefaniak, A., et al. (2019). Potential occupational hazards of additive manufacturing. Journal of 
Occupational and Environmental Hygiene, 16, 321-328. https:// doi.org/10.1080/15459624.2019.1591627

75. International Organization for Standardization (2006) Environmental management_Life cycle assessment_Principles and framework (14040)

76. Icha P, Kuhs G (2020) Development of the specific carbon dioxide emissions of the German electricity mix from 1990 to 2019 [Entwicklung der spezifischen Kohlendioxid-Emissionen des deutschen Strommix in den Jahren 1990-2019]. https://www. umweltbundesamt.de/sites/default/files/medien/1410/publikatio nen/2020-04-01_climate-change_13-2020_strommix_2020_fin. pdf. Accessed 08 May 2020

77. Ecoinvent (2020) Market for wastewater from black chrome coating in ecoinvent database 3.7.1. Ecoinvent association, Zürich

78. Althaus H-J, Chudacoff M, Hischier R et al. (2007) Life Cycle Inventories of Chemicals. ecoinvent report No. 8, v2.0. EMPA Dübendorf, Swiss Centre for Life Cycle Inventories, Dübendort

79. H2O GmbH. (2016). Spülwasser aus der Galvanik kostengünstig aufbereiten. JOT Journal für Oberflächentechnik, 56, 82-83. https://doi.org/10.1007/s35144-016-0135-2

80. German Federal Office of Statistics (2020) Fees for drinking water supply. https://www.destatis.de/DE/Themen/GesellschaftUmwelt/Umwelt/Wasserwirtschaft/Tabellen/tw-07-entgelt-trink wasserversorgung-tarifgeb-nach-tariftypen-2017-2019-land-bund. html. Accessed 12 Jan 2021

81. Keim, D., Andrienko, G., Fekete, J.-D., et al. (2008). Visual analytics: Definition, process, and challenges. In D. Hutchison, J.-D. Fekete, T. Kanade, et al. (Eds.), Information visualization: Human-centered issues and perspectives, vol 4950 (pp. 154-175). Springer.

82. Saha, R., Nandi, R., \& Saha, B. (2011). Sources and toxicity of hexavalent chromium. Journal of Coordination Chemistry, 64, 1782-1806. https://doi.org/10.1080/00958972.2011.583646

83. Lin, S. C., Tai, C. C., Chan, C. C., et al. (1994). Nasal septum lesions caused by chromium exposure among chromium electroplating workers. American Journal of Industrial Medicine, 26, 221-228. https://doi.org/10.1002/ajim.4700260207

84. Verein Deutscher Ingenieure (2014) Simulation of systems in materials handling, logistic and production (3633 Part 1)

85. Banks J (2010) Discrete-event system simulation, 5th ed., International version. Pearson Education, Upper Saddle River, London

86. Blume, S. A. (2020). Resource efficiency in manufacturing value chains. Springer.

87. International Organization for Standardization (2005) Workplace air. Determination of hexavalent chromium in airborne particulate matter. Method by ion chromatography and spectrophotometric measurement using diphenyl carbazide (16740:2005-02)

88. Thöming, J. (2002). Optimal design of zero-water discharge rinsing systems. Environmental Science and Technology, 36, 11071112. https://doi.org/10.1021/es010754t

89. German Federal Government (2004) Verordnung über Anforderungen an das Einleiten von Abwasser in Gewässer ( $A b w V)$

Publisher's Note Springer Nature remains neutral with regard to jurisdictional claims in published maps and institutional affiliations.

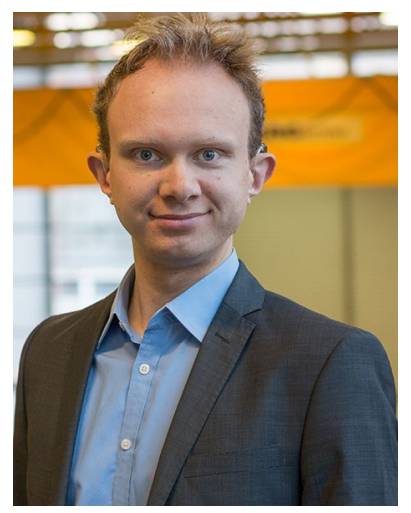

Alexander Leiden is a researcher in the group for Sustainable Manufacturing \& Life Cycle Engineering at the Institute of Machine Tools and Production Technology (IWF), Technische Universität Braunschweig. His research fields are model-based methods and tools in the context of digitalisation and industry 4.0 to foster sustainability in the plating industry. He is publishing as author and co-author for several scientific journals, books and conferences in his research field.

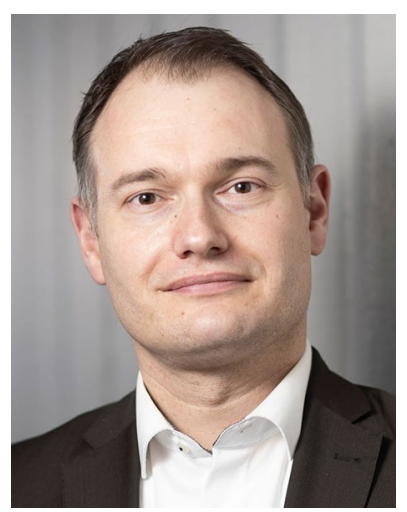

Sebastian Thiede is a full professor of Manufacturing Systems at the University of Twente within the Department of Design, Production and Management. Before, he headed the Sustainable Manufacturing research group at the Institute of Machine Tools and Production Technology (IWF) of Technische Universität Braunschweig. Professor Thiede conducted various projects in context of sustainability and digitalisation in manufacturing and published over 180 publications in scientific journals,

books and on conferences.

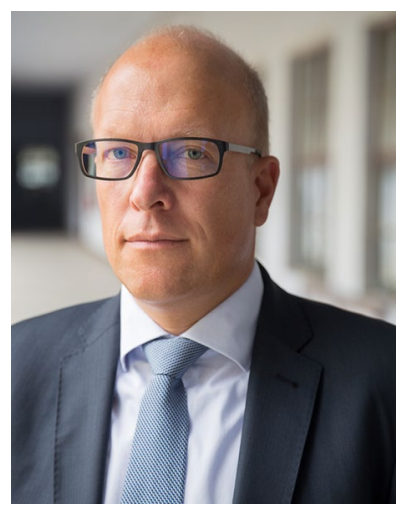

Christoph Herrmann is university professor for Sustainable Manufacturing \& Life Cycle Engineering and co-director of the Institute of Machine Tools and Production Technology (IWF) at Technische Universität Braunschweig as well as a member of the institute management at the Fraunhofer Institute for Surface Engineering and Thin Films (IST). Professor Herrmann has conducted various industry and research projects in the context of life cycle engineering and sustainable manufacturing on national and international level. He has published more than 300 papers and book publications as author, co-other and editor. Professor Herrmann is member of the International Academy for Production Engineering (CIRP). 